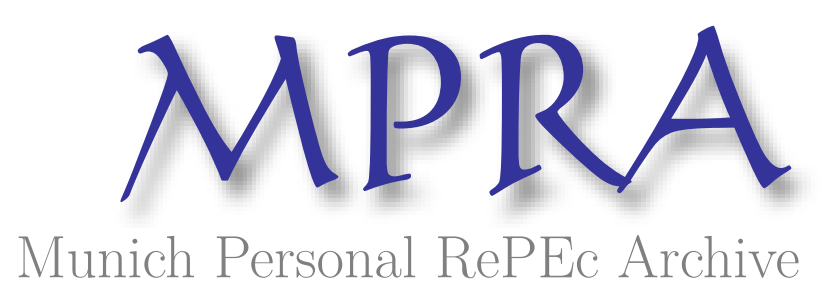

\title{
Effects of Consumer Financial Protection Introduced after the Financial Crisis of 2007-2008
}

Garcia Gonzalez, Javier

Universidad Carlos III de Madrid

27 September 2018

Online at https://mpra.ub.uni-muenchen.de/89226/

MPRA Paper No. 89226, posted 27 Sep 2018 19:03 UTC 


\section{Effects of Consumer Financial Protection Introduced}

\section{after the Financial Crisis of 2007-2008}

Javier Garcia Gonzalez

September 27, 2018

Universidad Carlos III de Madrid 


\begin{abstract}
This paper studies the effects of consumer financial protection regulation introduced in the US after the financial crisis of 2007-2008. It starts with a review of bounded rationality in the context of retail financial markets. I analyze the survey of consumer finances using diffs-in-diffs, paying special attention to the singularities of this dataset. The main goal is to assess the effectiveness of regulatory changes. Secondarily, the paper tries to find out if deception was occurring in the marketplace. There is support for the effectiveness of the 2011 FTC advertising rule. Results reject effectiveness of HOEPA rule of 2008 and HEOA provisions about private education loans.
\end{abstract}




\section{Notice}

This paper study is based on my master thesis at Universidad Carlos III de Madrid, which has the same title. You can find the code of this thesis at https://github.com/javiertury/cfpr-paper. 


\section{Introduction}

This paper studies consumer financial protection regulation proclaimed after the financial crisis of 20072008. The objective is to find out whether regulation was effective and if evidence is consistent with consumers being exploited. I will start with with a comprehensive review of academic work about the exploitation of rationally bounded agents in financial markets. Traditionally, the financial literature has assumed that all individuals are perfectly rational. Lack of information was the limiting factor to take better decisions, not cognitive abilities. However, there are cases in which individuals fail to take rational decisions in a persistent and systematic way, despite having complete information or taking frictions into account.

During the last decade, the increase in interest by academics has been matched by that of regulators. The US has experienced a wave of regulatory changes regarding consumer financial protection after the financial crisis of 2007-2008. Financial entities were blamed for this crisis, it was argued that consumers were being exploited and that some financial entities had incurred into predatory behavior. The FCIC report supported this point of view, although some members dissented.

The regulatory changes are consistent with the narrative in which consumers were misled or exploited by sophisticated lenders. Many of these regulations contain provisions to aid consumers at loan origination and these are the regulations that I will study. The provisions outlaw deceptive practices, ban false or inaccurate advertising, increase timely information disclosure, make information easier to digest by unsophisticated consumers and put restrictions on loan terms.

I will study a data sample representative of consumer credit transactions in the US. After managing the complexities of this dataset, I will perform an analysis. The objective is to uncover the effects of consumer financial protection regulation on market equilibrium. These results will be compared with the predictions of the theoretical models reviewed. The main hypothesis is that regulation is effective and therefore credit costs should decrease. Secondarily, effective regulation should not decrease credit availability which I will test for robustness. There is support in favor of the 2011 FTC advertising rule. Evidence rejects effectiveness of HOEPA rule of 2008 and HEOA provisions about private education loans. 


\section{Theory}

A sizable part of the behavioral finance literature has been rather descriptive, it identified biases and speculated about their sources. Recently, this field has developed more unified theories to explain those biases. Bounded rationally can easily and convincingly explain many of them in the area of economics, as argued by Conlisk (1996). The presence of boundedly rational agents in financial markets has important implications for the degree of efficiency, welfare of agents and imbalances generated for agents participating in those markets.

No individual or entity has unlimited and instant rational capability. However, the literature on fully rational agents is still applicable if this limitation is not binding. This may be the case of professional financial markets, like the stock market. Instead of rationality, information is key to model these markets.

The median citizen has lower financial education and cognitive abilities applicable to financial markets. These individuals have a large presence in retail financial markets posing as consumers. They are retail consumers of mortgages, mutual funds, insurance, etc. These consumers are heterogeneous in their degree of rationality, but in general they are boundedly rational. The suppliers of these financial products are firms with a higher degree of rationality.

Exploitation occurs when some individuals, the exploiters, change their behavior with the intent of becoming better off and make other individuals, the exploited, worse off. The exploiters change their behavior with respect to the scenario of perfect competition. Exploitation can be purposeful or not. Rational agents may have knowledge about the irrational behaviour of others and use it to maximize their own utility. Or the behaviour of rationally bounded agents may distort market incentives. This in turn could change the behavior of rational agents, even if they are unaware of the irrational behaviour of other agents. Exploitation is a word with strong moral connotation. Exploitation, like any other deviation from perfect competition, decreases social welfare.

Boundedly rational agents are not able to process all the information available. Instead they likely construct a simpler sparsity model, paying attention only to the most important variables as in Gabaix (2014). This could very well describe how consumers evaluate complex financial contracts. For instance, they could discard the fine print of a mutual fund and consider only the issuer, the segment and the cumulative return during the last 3 years. 
Bordalo, Gennaioli, and Shleifer (2012) develop a salience theory for lotteries in which consumers exhibit biased or irrational behaviours towards lotteries with salient attributes. Under this theory individuals overweight probabilities according to payoff salience. This model is able to replicate Allais paradoxes. Bordalo, Gennaioli, and Shleifer (2013) build a model for pricing risky assets upon this theory.

There is also empirical work on bounded rationality. The paper of Gabaix et al. (2006) uses an experiment to show that most of individuals take myopic decisions and are therefore rationally bounded. Results show heterogeneous groups in terms of rationality, some of them are more constrained than others. There is potential for deception if the less rationally constrained can profit from the more rationally constrained.

It is hard to conceive a model in which exploitation of irrational consumers is sustainable in equilibrium. However Eliaz and Spiegler (2006) showed that an exploitative equilibrium is possible. In the paper they show how firms can offer different contracts with the intention of discriminating customers according to their degree of rationality and successfully exploit naive customers.

\subsection{Add-on shrouding}

A central paper in this literature is that of Gabaix and Laibson (2006). In the paper naive consumers are exploited through deception. Some firms in the market split the product into a base good and an optional add-on. Naive consumers only take the price of the base good into account whereas sophisticated consumers take the price of both, the base good and the add-on, into account. If the price of the add-on is shrouded, sophisticated consumers form Bayesian posteriors. Before contracting they can do costly effort to find a substitute and choose not to buy the add-on.

There can exist a shrouded equilibrium in which naive customers are deceived. It is characterized by high shrouded add-on prices and low or negative markups for the base good. Loss-leader firms subsidize the base good and extract profits from the expensive add-ons that naive consumers buy. At the same time, sophisticated consumers profit from this scheme. Sophisticated consumers buy the subsidized base good below marginal cost and substitute the add-on. In terms of Armstrong (2015), these sophisticated consumers produce ripoff rather than search externalities on naive consumers.

This model is able to sustain a shrouded equilibrium if search costs are low, which contrast to the add-on model of Ellison (2005). Moreover, the equilibrium is sustainable under strong competition. If a firm 
sets prices equal to marginal cost, sophisticated consumers are still better off buying the subsidized good. Unshrouding or educating myopic consumers will make them sophisticated consumers. They will then prefer the loss-leader base good and substitute the add-on. The paper includes extensions to the model, like learning in an intergenerational model, and discusses other factors.

It's also interesting the fact that equilibrium separates naive from sophisticated consumers and creates price discrimination between sophisticated and unsophisticated consumers. Heidhues and Köszegi (2017) argue that price discrimination on investor sophistication either maintains welfare or lowers it, but welfare never increases.

Based on Gabaix and Laibson (2006), Heidhues, Kőszegi, and Murooka (2017) develop a model of competitive retail markets for a homogeneous product in which deception can occur. The product of this market is divided in two pieces, a base product which is paid upfront and an add-on which has an additional price and is paid later. In this model the add-on is mandatory and shrouded. There is also a price floor on the base product. A shrouded equilibrium is possible if consumers are myopic, and firms make positive profits when the upfront price floor is binding. Firms set the add-on price as high as possible, making existing myopic consumers valuable, and compete on the upfront price. They bid the upfront price down until it reaches the price floor.

Despite competition, this equilibrium is inefficient. Because of the price floor on the upfront price, firms would have to lower the add-on price in order to compete further. This doesn't happen in equilibrium. The reasons is that firms are required to unshroud add-on prices in order to communicate the discount to myopic consumers. Unshrouding can have negative effects for firms depending on the type of product. For socially wasteful products the market disappears and for other products it may reduce profits depending on the competitive environment.

The most interesting expansion is the multi-product market with both myopic and sophisticated consumers. Here firms offer a transparent product with a single price and a non-transparent product with an upfront cost and an additional cost to be paid later on. If the non-transparent product is an inferior good, then the transparent product is sold to sophisticated consumers making zero profits and the inferior good is sold to naive consumers at a profit.

Heidhues, Köszegi, and Murooka (2016) explore how deception affects innovation. There are two types of innovation considered in the paper. Value-increasing innovation increases the willingness to pay of 
consumers while exploitative innovation increases the firm markup. Cost-reducing innovations are considered a subset of markup-side innovations.

Markup-side innovations don't increase price competition and are always beneficial for the firm. That is, exploitative innovation is beneficial to the firm. Willingness-to-pay innovations, and hence valueincreasing innovations, don't have any effect with inelastic demand. Furthermore, the deceptive equilibrium can become unsustainable after a value-increasing innovation. In that case, a firm may be willing to pay to avoid that innovation.

\subsection{Agency}

Inderst and Ottaviani (2012) develop a model for agency conflict in retail financial markets. Here there are two product providers, one financial adviser and two types of customers. One of the product providers has competitive prices and the other acts like a monopoly. In contrast to the competitive provider, the monopolistic provider makes payments to the adviser. There is a fixed payment and contingent payments for each product sold.

The two types of customers are naive or wary. Naive customers don't believe that payments made by the monopolistic provider bias financial advice, but wary customers know. All type of customers pay a flat fee to the adviser. If there were only wary customers, the resulting equilibrium would imply unbiased advice, no sales commission and maximization of the total joint surplus of providers and customers.

Naive customers are stuck in an equilibrium with biased advice, sales commissions and in which the monopolistic provider maximizes profits in detriment of customers and social surplus. In equilibrium the adviser doesn't charge for advice, he only gets commissions from the monopolistic provider. When both types of customers are in the market, wary customers don't get advice. An efficient equilibrium for naive consumers can be achieved through regulation. Mandatory disclosure of commissions to intermediaries could make naive consumers become wary. A cap or ban on these commissions would also restore efficiency. However, the ban would be inefficient in the model of wary customers with effort provisioning.

This model can be compared to Gabaix and Laibson (2006). Here the base product, financial advice, is subsidized and the optional add-on is the financial product recommended. The difference of this model lies on a slightly different mechanism, here the base product doesn't require a shrouded add-on or a lock-in 
to a specific aftermarket. Deception occurs in the quality of the base product, financial advice, and this is what makes the customer buy the costly add-on.

Contrary to Gabaix and Laibson (2006), sophisticated consumers can't profit buying the base package and substituting the costly add-on. Unshrouding is not contemplated. However competition improves the accuracy of the recommendation and reduces fees. Competition in the market increases with the number of advisors and elasticity or sophistication of demand.

This is in line with the criticism of the literature on intermediated financial markets. Philippon (2015) explores historical intermediation efficiency and shows that intermediation efficiency hasn't improved significantly despite all of the progress in the IT sector. Others have shown that intermediation can still appear even if it doesn't add value, for example Edelman and Wright (2015) show how price coherence contracts result in excessive and wasteful intermediation.

It is worth mentioning the possibility of consumers seemingly overpaying for trust, without any deception or agency conflict. This is the case of money doctors as modelled in Gennaioli Nicola, Shleifer Andrei, and Vishny Robert (2015). At much, money doctors accommodate to investor's incorrect expectations but don't induce them.

\subsection{Overconfidence and inattention}

Deception is not the only way through which exploitation can occur. DellaVigna and Malmendier (2004) discuss how rational firms can exploit overconfident consumers that are time inconsistent. This time inconsistency stems from a quasi-hyperbolic discount function. Unsophisticated agents that are unaware of their time inconsistency will be overconfident in their decisions. They will easily be led towards overconsumption of leisure goods and overprovisioning of investment goods. For leisure goods, firms just have to design contracts that postpone payment. For investment goods, firms have to anticipate consumer commitment for capacity which won't be used later.

Closely related to overconfidence is inattention. Gabaix (2017) does a deep and insightful review of the literature on inattention. The emphasis is on economics and provides a general framework for modelling different types of inattention. These are inattention to shrouded add-on costs, taxes, risks, the future, probabilities, conditional probabilities, own ability, future circumstances, base rate, correlation, sample 
size, randomness, autocorrelation, non-leading digits and exponential growth.

Grubb (2015) shows how firms can take advantage of naively inattentive consumers through carefully crafted contracts. These consumers are naive about their inattention. Entering the contract has a fee which can be positive or negative. There are two periods for consumption. Consumption on the first period affects the price of consumption in the second period. In the case of surprise penalties, the price of consumption in the second period increases with consumption in the first period. In the case of loyalty discounts it decreases. Naive inattentive consumers think they will be attentive at the time they sign the contract, but later they are not.

Consumers suffer a taste shock each period and guide their consumption under their estimated marginal utility. Contracts with surprise penalties make naively inattentive consumers incur into penalties during the second period with a probability higher than predicted. The contract will also make consumers overzealous and miss second period consumption when they don't have a penalty.

With loyalty discounts, naively inattentive consumers make on average higher than optimal consumption in period two because they believe they have a discount when they don't have it. They also overestimate the probability of avoiding the high cost of a first unit. In equilibrium, naively inattentive consumers subsidize everyone else and induce allocative distortions for attentive consumers that want to avoid charges.

The model is related to Bill-shock regulation which mandates that consumers be notified of increases in marginal cost at the point of purchase. For example, notifying consumers of the costs of bank account overdrafts when they make a purchase. In this model the regulation is equivalent to making every consumer attentive. It eliminates the subsidy that naively inattentive consumers pay and eliminates the socially inefficient distortions that attentive consumers do in order to avoid charges. In general it increases social welfare. If firms were doing price discrimination thanks to consumers being unaware of their prices, Bill-shock regulation could lower welfare.

\subsection{Choice complexity, comparability and obfuscation}

Firms can use less sophisticated strategies to exploit rationally bounded individuals. For instance, they can overload the cognitive capacity of consumers to diminish comparability among products. This in turn lowers competition, increasing market power and profits. Spiegler (2016) is a good reference on choice 
complexity.

Real life financial services are complex and so are their pricing structures. Firms may use this complexity to shroud costs or to relax the competitive environment. Carlin (2009) creates a model in which firms use complexity to increase market power for financial products and this complexity increases with competition.

In more detail, the model of Piccione and Spiegler (2012) describes price competition under limited comparability. Here firms choose price and price format, which consumers will use to compare firms. Differentiation is not about satisfying consumer heterogeneous tastes, it's about obfuscating the real price to avoid Bertrand competition.

In a sequential game, firms undercut the price of rivals and select a comparable format. In a simultaneous game, firms don't want to be comparable to the rest so price format complexity becomes unnecessarily high. In equilibrium, firms randomize price format and choose a positive price in order to obtain profits. Decisions about price format and price are generally independent, improvements in comparability lead to higher switching rates and increase consumer welfare. These results do not necessarily hold in the presence of multiple price format categories if weighted regularity is violated. For example, increasing format comparability on only a subset of formats can have negative effects on consumer welfare, as firms move to more complex format categories.

Carlin and Manso (2011) present a model of obfuscation in the context of dynamic learning and homogeneous products. There are two types of investors, exogenously informed investors and initially uninformed investors. Uninformed investors can become informed by learning. The effect of learning is temporary and there are two sub-models depending on whether investors learn by themselves or through other informed investors.

Informed investors choose the product with lowest fees while uninformed investors choose randomly. In aggregate, uninformed investors accumulate knowledge over time. The provider of products can reset the knowledge that initially uninformed investors have learnt so far, this event is called obfuscation. The provider incurs into a cost each time he obfuscates the attributes of the products.

In equilibrium the provider periodically obfuscates at the optimal stopping time of the problem. Obfuscation frequency occurs more often when the provider incurs lower costs. The relationship between optimal obfuscation frequency and learning rate has an inverse $U$ shape. Obfuscation increases with learning rate 
up to a inflexion point over which higher learning leads to lower obfuscation.

There is another specification in which only a reduced subset of the population participate in the market for these products. As time passes, the product becomes more widespread and more consumers enter the market. Obfuscation has the side effect of resetting the fraction of consumers that entered the market. This reduces incentives to obfuscate.

Contrary to Carlin (2009) obfuscation decreases as the number of competitors increases. In another specification the fraction of initially informed investors is endogenous. This and other variations of the base model are also discussed in the paper.

\section{Empirical Literature on Mortgages and Loans for Durable Goods}

Woodward and Hall (2012) perform a non-conventional but illustrative study on the market of broker sold mortgages. Mortgage brokers receive compensation from lenders contingent on loan interest rate, known as Yield Spread Premium(YSP). They argue this gives brokers an incentive to increase borrowing costs for borrowers, even if borrowers are already compensating the broker with cash origination charges. This scenario is similar to the intermediated model of Inderst and Ottaviani (2012), but the model is quite different. The model is built around the bargaining process, in which a borrower negotiates with multiple brokers in an English or second-price auction. Total costs for the borrower are stochastic, and the distribution of costs depends on the number of rival brokers included in the auction. It's the borrower that chooses how many brokers to include in the auction, incurring into a cost for each broker added.

They estimate the number of rival borrowers from the empirical distribution of borrowers' total costs. The distribution parametrized with 2 rival brokers is the most plausible one given the characteristics of the market. They also predict that including more brokers in the auction would significantly reduce borrowers' costs. Data used in the paper was provided by the Federal Housing Administration(FHA), which insures mortgages. The period of the study is 2000-2001 since compensations from lenders to brokers were outlawed by the Real Estate Settlement Procedures Act of 2002, 12 U.S.C. \$2607. However, they criticized the law for not having real effects on vertically integrated lenders and allowing to partially shroud broker charges labeling them as discount points instead of origination charges.

Additionally, they document that many consumers don't understand how the market works. They hypoth- 
esize that consumers shop better when price has a single dimension instead of two and find support for the hypothesis. This is similar to an improvement of price comparability under Piccione and Spiegler (2012).

Before I mentioned discount points. Many lenders allow borrowers to buy discount points at mortgage origination. Each point has a non-standardized price at loan origination and entitles the borrower to a non-standardized reduction on the loan interest rate through the total duration of the loan. Commonly, the first discount point gives the right to a $0.25 \%$ interest cut. There are negative or reverse discount points which are paid with a non-standardized increase on the interest rate for the total duration of the loan and give the borrower a non-standardized rebate to pay origination charges.

Agarwal, Ben-David, and Yao (2017) show that buying discount points yields a negative net present value(NPV) on average. Borrowers are on average better off taking smaller loans at the initial interest rate than asking for a larger loan to pay for discount points. Data is obtained from an undisclosed US mortgage insurer and taxes are taken into account for calculations.

Despite these results, a minor but sizable proportion of borrowers buy discount points. It is clear that buyers of discount points are unsophisticated. However they are not myopic, it is the opposite. This poses a challenge to Gabaix and Laibson (2006) but easily fits the case of overprovisioning investment goods of DellaVigna and Malmendier (2004).

Discount points add another price dimension to the mortgage search process, making it more difficult to compare. They are also used to advertise low mortgage APRs, obfuscating the price of these discount points in the fine print.

Gurun Umit G., Matvos Gregor, and Seru Amit (2016) show that the overall informational content of mortgage advertisements is very low. Also they find that lender expensiveness is positively associated to advertising intensity. These results challenge the informational role of advertising in favor of a persuasive role. Loans usually have a lower introductory interest rate during the first months and a reset interest rate after this period. Reset rates are absent in mortgage advertisements while lower introductory rates are more prominent. Sometimes APRs are published, although guiding decisions using advertised APRs leads to more expensive lenders on average.

Stango and Zinman (2011) study loans financing the purchase of household durable goods. A key event of this study is the Truth In Lending Act(TILA) reform of 1981 in which the requirement to advertise APR continued to be well enforced for banks but became laxer for other finance companies. The data used 
in the paper is household panel data that comes from the 1983 Survey of Consumer Finances(SCF). It includes questions that measure the bias that households have in converting monthly payments to implicit interest rates, which is used as a proxy of financial sophistication.

They then proceed with a diffs-in-diffs regression of APR. The independent variables are dummy indicators for financial companies, post TILA reform period, household sophistication and interactions between. There are also control variables and household fixed effects. The difference between the interest rates of comparable more-biased and less-biased consumers grows significantly after regulation becomes softer. Results suggest that overall interest rate decreases after the reform takes place. This shows that regulations can also impose costs on consumers, even if they intended to protect them.

\section{Effects of Regulation on Consumer Credit Markets}

I will review what are the effects of regulation under each family of models in order to formulate the hypotheses of this study. Consistent with the vision maintained so far, I assume that retail financial markets can be decomposed into a demand side comprised of consumers and a supply side composed mainly of businesses. These consumers are heterogeneous but most of them are naive. The degree of rationality of consumers is bounded below that of businesses. Both supply and demand reach a market equilibrium.

The regulation that I consider can be informative or restrictive. Informative regulation mandates or encourages the timely disclosure of useful and digestible information to consumers. Timely information gives consumers more time to process the information, allows them to discover shrouded costs and can reduce complexity. Standardized disclosures facilitate comparison. Information can be disclosed as early as the loan is advertised or as late as moments before closing the loan.

Restrictive regulation prohibits or discourages certain loan terms and practices. When lenders rely on certain contract terms to shroud costs, restricting these terms can preclude shrouding. Restrictions can reduce complexity of contracts and reduce the choices that lenders have for obfuscation. Regulating practices is also important. For instance, lenders or brokers can influence third parties like appraisers to maximize their own utility at the expense of the consumer. Or consumers can fall into the sunk cost fallacy because of fees owned before contract closing.

The first family of models is composed of models related to agency conflict. The scenario regulated is 
similar to the model of Inderst and Ottaviani (2012). Consumers use an intermediary to obtain a loan from a lender. Both the intermediary and the lender are sophisticated. The customer enters into a contract with the intermediary to find and obtain the loan that would maximize his utility.

The utility of customers is given by credit availability and credit costs. Costs are in turn given by interest rate and fees. The utility of the consumer increases as interest rates decrease, as fees decrease and as the conditions that trigger those fees are more restricted. A conflict can arise if the compensation mechanism from lender to intermediary provides incentives to diminish the utility of the borrower. Yield spread premium commissions are an example of such a compensation mechanism.

Inderst and Ottaviani (2012) propose a cap or ban on commissions between lenders and intermediaries to end the conflict and restore efficiency. Informative regulation can be ineffective if consumers remain unaware of the full agency problem, are inattentive or are not able to process the information, since they are boundedly rational. If regulation is effective, rents would dissipate and loan costs for naive customers should be reduced. The model doesn't contemplate changes to credit supply or credit demand. Competitive credit supply shouldn't be affected beyond compliance costs, as the cost of money is the same.

The second family of models is those based on the add-on model of Gabaix and Laibson (2006). These shrouded add-ons can be optional or mandatory. An example of optional fees are excessive late fees, which are only triggered in the case that the consumer delays a repayment. The other type of fees, mandatory fees, are widespread. For instance, government direct student loan programs charge a fee over the amount loaned. That fee is not paid at origination, but rather amortized during the term of the loan. For mortgages, origination fees are the most common type of mandatory fees.

Effective regulation will drive credit costs down. In this case, supply is not affected. Unshrouding will make consumers realize that the real price of the good is higher than they thought, and demand will fall. This in turn will decrease overall market size and lower borrowing costs even further if supply is upwards slopping.

The third family of models embraces those in which lenders use artificial complexity or obfuscation to discourage comparison and obtain market power. They obtain profits at the expense of consumers. Lenders can be creative about the terms of the loan, the representation of credit costs in advertisements, the name of the fees and the conditions under which the fees apply.

In standard economic models, market power will increase credit costs and diminish credit availability. 
Regulation can decrease or increase market power of lenders, and in terms of consumer financial protection, regulation would be effective if it decreases market power. This will cause credit costs to diminish and credit supply to increase. Assuming credit demand is downwards sloping, consumers will borrow more and new consumers can also enter the market as their expected utility increases above the reservation utility. Therefore the credit market should grow.

The models of artificial complexity and obfuscation are similar to economic models of market power. Instead of fixing prices or limiting supply, lenders overburden the cognitive capabilities of borrowers, which hinders comparability. Lenders can leverage that market power by constraining supply. Effective regulation should also decrease credit costs and possibly increase credit supply. If credit demand is downwards sloping, demand will grow and hence the credit market should also grow.

In general, I will make the following hypotheses. The null hypothesis is that regulation is ineffective or there was no exploitation. Under this hypothesis, total loan costs should not decrease for consumers as the market was already competitive. Consumers already process all the information they needed and giving more timely information to consumers would only create costs for lenders. In this scenario banning certain loan terms or compensation mechanism can only introduce frictions. The direct and indirect costs of regulation will be borne partly by borrowers who will have to accept higher costs and may be driven out of the market.

The alternative hypothesis is that consumers were exploited and regulation about intermediation or direct compensation is effective. Loan costs should decrease. Notice that regulation can be effective even if it has no effect on direct costs, i.e. interest rate. Regulation that eliminates indirect costs such as shrouded fees reduces borrowing costs for consumers. Regulatory changes can have two effects, they can change the applicable regulations and they can change which loans are covered by the regulation. In the case that both applicable regulations and coverage are modified, I argue the effect for newly covered loans should be larger than for previously covered loans.

Additionally I will conduct a robustness test. Credit availability is important for consumers and none of the models contemplate a shrink in credit supply because of effective regulation. If empirical evidence shows with a high confidence level that credit supply remained constant or increased after the regulation, I will consider previous evidence in favor of the alternative hypothesis to be robust.

Later I will analyze consumer demand, as only the model about add-on deception predicts that demand 
can shrink due to effective consumer protection regulation. In that scenario, demand falls and credit costs decrease while credit supply doesn't fall. This scenario implies that regulation is effective and that deceptive practices were in place at the consumer credit market.

This reasoning should be intuitive. If credit conditions improve, consumer protection regulation is effective. If despite these improvements consumers don't want the product, it means consumers were previously being deceived and they have learned about it. After regulation effectively removes deception, consumers see real costs and choose not to borrow.

\section{US Regulatory Framework after 2007}

Exploring regulatory changes requires cautious attention. These changes can derive from legislative acts or from rules issued by competent rulemaking authorities. The date in which a rule is issued or an act is enacted may not be the same as the effective date of the provisions. Apart from an effective date, provisions may specify a mandatory compliance date. Provisions under the same act or rule can have different effective or mandatory compliance dates. These dates can be modified by subsequent regulations.

The same attention paid to dates must be paid to the content of provisions. Generally a regulatory change can have two effects, the first one is a modification of applicable regulations. An example is requiring more timely information disclosure or prohibiting certain terms. The second one is a change in coverage. For instance, applying existing provisions that only covered mortgages given by banks to mortgages given by finance companies. Often regulatory changes do both, modify applicable regulations and modify coverage. In these cases, dividing loans by regulatory coverage can increase the precision of the study. Let's assume that the regulatory effect is identical on all loans and there has been an expansion in coverage. The change in coverage allows to estimate both the effect of old provisions and the difference between new and old provisions. The change on previously covered loans corresponds to the difference between the effect of new and old provisions. The change on newly covered loans minus the change on previously covered loans is the effect of old provisions.

The institution in charge of enforcing the regulation can influence the final effect of that law. Therefore, attention should also be put on enforcement.

One of the most remarkable regulatory changes is also outside the scope of this paper. The Dodd-Frank 
Wall Street Reform and Consumer Protection Act was passed into law on July 21, 2010. This bill set the creation of the Consumer Financial Protection Bureau(CFPB) which started its operations one year later. The bill also transferred rulemaking and enforcement authority to the CFPB, thereby centralizing regulation and enforcement into a single institution. Many institutions that held enforcement authority previous to the Dodd-Frank act, retained it. For example, the FTC and the CFPB share enforcement authority regarding regulation N. Some institutions that held rulemaking authority before the Dodd-Frank Act retained it for certain provisions. This is the case of the FRB, which retained rulemaking authority under regulation $\mathrm{Z}$ for specific cases, like loans made by some motor vehicle dealers. The Office of Thrift Supervision was eliminated by Dodd-Frank act.

In this study I will ignore the Dodd-Frank Act for two reasons. First, the Dodd-Frank act tasked the CFPB with the creation of many consumer protection rules that became effective in late 2013 and 2014. They fall outside of the period considered in this study. Second, enforcement actions by the CFPB started in late 2012, almost at the end of the period considered here. I assume that the additional enforcement effect exerted since late 2012 by the CFPB is similar for all loan types. This effect should be captured by year dummies. All regulatory changes considered in this study are effective before the CFPB started enforcement actions and are not contaminated by this event. Note that between 2012 and late 2013 no important regulatory changes enter into effect.

Of all the regulations the most important one is regulation Z(TILA). Other regulations that I will include in this study are the regulation $\mathrm{G}$, regulation $\mathrm{H}$, regulation $\mathrm{N}$ and regulation $\mathrm{X}$.

Table 1: Regulation name and original acts

\begin{tabular}{ll}
\hline Regulation & Act \\
\hline Regulation B & Equal Credit Opportunity Act \\
Regulation C & Home Mortgage Disclosure Act(HMDA) \\
Regulation D & Alternative Mortgage Parity \\
Regulation E & Electronic Fund Transfers Act(EFTA) \\
Regulation F & Fair Debt Collection Practices Act
\end{tabular}

Regulation G

Regulation H
Secure And Fair Enforcement(SAFE) Mortgage Licensing Act Federal Registration of Residential Mortgage Loan Originators

Secure And Fair Enforcement(SAFE) Mortgage Licensing Act -

State Compliance and Bureau Registration System 


\begin{tabular}{ll}
\hline Regulation & Act \\
\hline Regulation I & Disclosure Requirements for Depository Institutions Lacking \\
Regulation J & Federal Deposit Insurance \\
Regulation K & Purchasers' Revocation Rights, Sales Practices and Standards \\
Regulation L & Special Rules of Practice \\
Regulation M & Consumer Leasing \\
Regulation N & Mortgage Acts and Practices-Advertising(MAPs) Rule \\
Regulation O & Mortgage Assistance Relief Services(MARS) \\
Regulation P & Privacy of Consumer Financial Information \\
Regulation V & Fair Credit Reporting \\
Regulation X & Real Estate Settlement Procedures Act(RESPA) \\
Regulation Z & Truth in Lending Act(TILA) \\
Regulation DD & Truth in Savings Act \\
\hline
\end{tabular}

Previously, the distribution of enforcement and rulemaking authority was distributed among many institutions. Each regulation could grant rulemaking or enforcement authority to any separate institution, and make it contingent on lender type. The choice was not arbitrary, in general authority was transfered to institutions which previously held jurisdiction over those lenders. Under the Truth In Lending Act rulemaking authority was granted to the Federal Reserve Board(FRB) while enforcement authority was distributed as follows.

Table 2: Enforcement authority under TILA

\begin{tabular}{ll} 
Regulated lender & Enforcer \\
\hline Member banks of the Federal Reserve system and foreign & Federal Reserve Board(FRB) \\
banks & \\
National banks & Office of the Comptroller of the \\
& Currency(OCC) \\
Saving associations(thrifts) & Office of Thrift Supervision(OTS) \\
Federal credit unions & National Credit Union Administration(NCUA) \\
Air carriers & Secretary of Transportation
\end{tabular}


Regulated lender

All remaining
Enforcer

Federal Trade Comission(FTC)

\subsection{Regulatory Changes}

The Truth in Lending Act was enacted in 1968. It was been reformed several times since its inception, although I will only describe a few amendments. On 1980 the Truth in Lending Simplification and Reform Act was enacted. Most provisions became effective on 1981 April 1, an event which was studied by Stango and Zinman (2011).

Another important amendment to TILA was the Home Ownership and Equity Protection Act(HOEPA) of 1994 to prevent abusive practices in refinances and closed-end home equity loans. The objective was to curve the increase in predatory lending since the mid-1990s. There were loans with high interest rates granted to consumers who could not repay them. Mortgage agents encouraged repeated refinancing in order to obtain fees regardless of consumers' welfare. They often bundled other financial products without the consumer knowledge, which increased financing costs. HOEPA grants additional protections to consumers of loans that surpass specified interest rate and fee triggers. Originally, it applied to closedend home equity loans and refinances secured by the consumer's principal residence, excluding home purchase loans. The protections include additional timely disclosures and restrictions on applicable loan terms.

The FRB issued a final rule for HOEPA in 2001 to change APR thresholds, expand the fee based trigger and include other provisions. The threshold for first-lien loans was lowered from $10 \%$ above comparable treasury securities to $8 \%$, while the threshold for subordinate-lien loans remained at $10 \%$. Mandatory compliance was required in October 1, 2002.

The HOEPA final rule issued on July 30, 2008 extended higher-priced mortgage provisions coverage to any closed-end mortgage loan secured by consumer's principal dwelling except construction-only loans. Provisions regarding high-cost mortgages are effective since October 1, 2009. The rule added more provisions applicable to high-cost mortgages. These are more strict verification for ability to repay, a general prohibition of prepayment penalties and a change in the threshold used to determine high-cost mortgages. A first-lien loan is higher priced if the APR is $1.5 \%$ above the average prime offer rate(APOR) index 
published by Federal Reserve. The threshold for subordinate-lien mortgages is 3.5\% above APOR. The rule required creditors to establish escrows for taxes and insurance for higher-price mortgages since April 1, 2010. It's prohibited to structure closed-end mortgages as open-end lines of credit to evade these rules.

This last rule contained many more provisions, some of them applicable to non high-cost mortgages as well. It set higher advertising standards about rates, monthly payments and other loan features. These advertising provisions are applicable to open-end credit secured by a consumer's main dwelling and to all closed-end mortgages since October 1, 2009. At the same date, the rule sets a prohibition for creditors and brokers to influence appraiser or pyramiding late fees in connection to loans secured by a consumer's principal dwelling.

Hypothesis 1. After October 1, 2009 (HOEPA08), consumers should see a decrease in the costs of closed-end secured loans due to advertising provisions. High-cost provisions should make the decrease stronger for loans secured by the consumer's principal dwelling. The decrease should be even more noticeable on newly covered loans, that is, loans intended to finance the purchase or initial construction of a consumer's main dwelling which excludes refinances.

Lastly, it broadened the set of loans subject to RESPA that must provide timely information disclosures. Previously, this disclosure applied only to loans subject to RESPA and used to finance the purchase or initial construction of a consumer's principal dwelling. Effective in July 30, 2009, the timely disclosure were extended to any loan subject to RESPA and secured by the consumer's principal dwelling. I will study these provisions together with those of MDIA.

The MDIA was enacted in 2008 to amend TILA and most provisions became effective on July 30, 2009. It is applicable to any closed-end loan covered by RESPA and secured by a dwelling other than the consumer's principal dwelling, since they were covered by HOEPA 2008 final rule. However both of them are effective at the same time and have similar provisions. Home Equity Lines of Credit(HELOC) are excluded. Previous to MDIA, early disclosures were only applied to a residential mortgage transaction subject to RESPA. That is, loans used to finance the purchase or initial construction of a consumer's principal dwelling.

MDIA restricts initial fees to reasonable credit report fees. Any lender covered by MDIA must issue the no requirement to complete statement that previously was only required for high-cost loans under HOEPA. Previously, initial disclosures under HOEPA had to be made 3 business days prior to consummation of 
high-cost loans. MDIA requires 7 business days for initial disclosures and 3 business days for corrections. All of the Truth In Lending(TIL) statements must be reissued if APR changes beyond a certain threshold. MDIA contains special provisions for variable rate loans which are effective on January 30, 2011. The cost of variable rate mortgages is lower than that of fixed rate mortgages. Lenders and brokers offer these loans to consumers focused on interest rates. However consumers may not be fully concious about the risks that floating rates entail. By shifting interest rate risk to consumers, lenders and brokers would be effectively hiding credit costs. On January 30, 2011 a Federal Reserve rule consolidated, clarified and revised MDIA provisions for adjustable-rate loans. Compliance with the second rule is mandatory since October 1, 2011.

The SCF 2013 dataset used in this study doesn't provide information about RESPA status of loans. I can only identify if the first mortgage secured by a consumer's main dwelling is known to be government related and therefore subject to RESPA. This doesn't mean that remaining loans are not government related, they are just not known to be government related. I decided to ignore or lower the priority of RESPA status in the formulation of hypotheses.

Hypothesis 2. After disclosure provisions on RESPA loans contained in MDIA and HOEPA 2008 become effective(MDIA), consumers should see a decrease in the cost of mortgages. The effect should be more noticeable on newly covered loans, that is, loans secured by a secondary dwelling or not intended to finance the purchase or initial construction of a consumer's main dwelling.

Hypothesis 3. After January 30, 2011 (MDIA2), consumers should see a decrease in the cost of variable rate loans secured by any dwelling. This decrease should be more noticeable on loans known to be government related.

The Real Estate Settlement Procedures Act(RESPA) of 1974 was an important milestone on consumer financial protection. RESPA covers federally related mortgages and grants rulemaking authority to the department of Housing and Urban Development(HUD). Disclosure requirements vary according to the type of loan. The most important disclosures are for mortgages used to finance the purchase or initial construction of a consumer's principal dwelling. Soon after receiving an application for these mortgages, lenders must disclose Good Faith Estimates(GFE) of settlement costs. Before closing, borrowers should receive a HUD-1 form with actual costs. If the difference between HUD-1 and GFE surpasses a certain threshold, consumers are entitled to a refund. Kickbacks and referral fees are prohibited. 
On November 17, 2008 the HUD published a rule amending RESPA. Provisions are effective on January 16, 2009 but the implementation of the new GFE and HUD-1 forms is required on 2010 January 1. It also broadens the definition of a mortgage broker. Later, the Dodd-Frank Act mandated other changes to RESPA which were implemented after the period considered in this study. It shortened time limits, increased penalties and more.

Hypothesis 4. After January 1, 2010 (RESPA08), consumers should see a decrease in the cost of mortgages. This decrease should be stronger for loans known to be government related, and therefore subject to RESPA.

On August 16, 2010 the Federal Reserve Board issued a final rule about loan originator compensation practices. It was scheduled to become effective on April 1, 2011 but was amended and became effective on April 6, 2011. The rule prohibits payments to loan originators on terms or conditions of the loan other than the amount of credit extended. Previously, only loans tied to the consumers' principal dwelling were protected. With this rule, protection applies to closed-end loans secured by any dwelling including mobile homes. The rule excludes time shares, HELOCs and loans secured by real estate which is not a dwelling.

Hypothesis 5. After April 6, 2011 (CompBan), consumers should see a decrease in the cost of closedend loans secured by secondary dwellings or mobile homes.

In 2008 the Higher Education Opportunity Act(HEOA) was enacted. To implement certain provisions regarding Private Education Loans(PELs), TILA was amended on July 30, 2009. The provisions are effective since September 14, 2009 and compliance was required after February 14, 2010. This regulation applies to any loan for which any portion of the borrowed amount is used to pay post-secondary educational expenses. These expenses includes tuition, fees, books, supplies, room, board or miscellaneous personal expenses. Doesn't include open-end consumer credit plans or credit secured by real property

Preferred Lender Arrangements(PLA) are lenders recommended by an educational institution. Loans from government programs and loans funded by the educational institution's own funds or donor-directed contributions are exempted. PEL provisions require educational institutions to make some timely disclosures if the institutions have PLAs or don't provide neutral information about different loan providers. They are obliged to disclose information about government loan programs, standard TILA disclosures and inform students that they don't need to borrow from the preferred lender. Lenders are subject to a number of restrictions. They can't offer personal loans that guarantee the concession of a PEL or improve the 
terms of a PEL. Lender must obtain a self-certification form provided by the educational institution to the student before loan consummation. This form contains many disclosures and information. Co-branding is prohibited, revenue sharing and gifts are also prohibited.

Hypothesis 6. After February 14, 2010 (HEOAPEL), consumers should see a decrease in the cost of educational loans. Non-secured loans and open-end consumer credit plans are excluded.

On July 1, 2010, just at the start of the award year, four final HEOA rules amending federal programs became effective. These rules were approved on October 27, 28 and 29 of 2009. One of these rules clarifies the disclosures that educational institutions must provide to the students about loans.

HEOA also requires educational institutions receiving federal funds to offer an online net price calculator. This tool provides information to students about most costs related to education, room and board, materials and other expenses, as well as information about grants and federal loans. The calculator is mandatory since October 29, 2011. This tool informs students about grants and federal loans, which expands their range of options and increases credit competition. Probably, this regulation will have a stronger effect on loans granted or endorsed by educational institutions.

Hypothesis 7. After October 29, 2011 (HEOACalc), consumers should see a decrease in the cost of educational loans, specially those provided by educational institutions.

The Safe And Fair Enforcement(SAFE) Mortgage Licensing Act of July 30, 2008 requires nationwide registration of any individual who acts as a residential mortgage loan originator (MLO) and is employed by a financial institution. Initial registration of mortgage loan originators starts on 2011 January 31 and is compulsory on July 29, 2011. Federal registration is required for any MLO employed by an institution regulated by either the FRB, OCC, OTS, NCUA, the Farm Credit Administration(FCA) or the Federal Deposit Insurance Corporation(FDIC). State registration is required for the rest of MLO. It covers loans secured by a dwelling or real estate to be constructed as a dwelling.

Hypothesis 8. After July 29, 2011 (SAFE), consumers should see a decrease in the cost of mortgages. The Omnibus Appropriations Act of 2009 granted the FTC authority with respect to regulation N. The Credit Card Accountability Responsibility and Disclosure Act(CARD) of 2009 clarified that such authority was granted with the purpose of regulating unfair or deceptive acts or practices regarding mortgage loans. The FTC issued a final rule, which is effective since August 19, 2011, banning deceptive claims and material misrepresentations about consumer mortgages. This rule doesn't cover banks, thrifts, federal 
credit unions or non-profits. It includes closed and open(HELOC) mortgages, as well as forward and reverse mortgages. The most important part is that the FTC was encouraged to enforce these rules and was allowed to collect the penalties specific to mortgages. Most of the acts or practices considered deceptive were already illegal and the FTC had authority to enforce rules about advertising.

Hypothesis 9. After August 19, 2011 (AdRuleFTC), consumers should see a decrease in the cost of mortgages provided by institutions subject to FTC advertising regulation. This excludes banks, thrifts, federal credit unions and non-profits.

Some events or regulatory changes that are not interesting for this study still have to be controlled for. On May 20, 2009 Helping Families Save Their Homes Act(HFSTH) was enacted. It contains a cram down provision which expands eligibility for chapter 13 bankruptcy. This could have side effects for mortgages on primary residences. Lenders may increase borrowing costs to compensate for additional risk or cut credit supply to less worthy borrowers.

\section{Data}

Table 3: Summary Statistics for SCF 2013 Dataset

\begin{tabular}{lrrrrrrr}
\hline Variable & Mean & Quartile 1 & Median & Quartile 3 & Min & Max & SD \\
\hline Interest Rate & 5.72 & 3.40 & 4.70 & 6.50 & 0.09 & 23.00 & 3.96 \\
Implicit Int. Rate & 8.58 & 4.20 & 7.02 & 10.34 & 0.00 & 39.81 & 6.92 \\
Annuity Bias & -0.04 & -0.14 & -0.03 & 0.04 & -0.89 & 0.98 & 0.17 \\
Payment Amount & 8172.43 & 310.00 & 600.00 & 1400.00 & 0.00 & 15980000.00 & 272109.32 \\
Yearly Pay Freq. & 12.12 & 12.00 & 12.00 & 12.00 & 1.00 & 52.18 & 2.05 \\
Balloon Payment & 200964.28 & 82500.00 & 289000.00 & 902500.00 & 290.00 & 167820000.00 & 13205865.93 \\
Eq. Risk Free Rate & 2.46 & 0.93 & 2.52 & 3.85 & 0.16 & 5.07 & 1.48 \\
Eq. Corporate Rate & 3.18 & 1.28 & 3.08 & 5.05 & 0.30 & 6.92 & 1.90 \\
Maturity & 12.54 & 3.00 & 6.00 & 30.00 & 0.00 & 57.00 & 11.79 \\
Adj. Amount & 297002.08 & 14208.37 & 34804.06 & 171366.34 & 75.73 & 227471861.04 & 4123729.63 \\
\hline
\end{tabular}

In general data belongs to the period from 2005 to 2013. The main data set of this study is the Survey of Consumer Finances of 2013, which belongs to a series of surveys published by the Federal Reserve Board every three years. This is a cross-sectional survey of US families with information about demographic characteristics, debts, income, pensions and assets of surveyed individuals. It contains data about the type of loan, interest rate, amount borrowed, payment schedule, payment amounts, type of lender, date of origination and other details specific to each loan type. Individuals can provide details about multiple 
loans, whether they are of the same type or not. I assume that loans used to buy properties are mortgages. There are mortgages, automotive loans, student loans and other consumer loans. The dataset provides some weights that make the sample representative of the whole US consumers.

Although SCF data is a cross-sectional survey, it can be converted to panel data. This conversion relies on the fact that each household can report information about multiple loans originated at different points in time. In this dataset each observation is multiply imputed and has 5 imputation replicates. There are replication weights for each observations which simulate 999 sample replicates using bootstrap. The weights take into account the survey design of this sample. This data requires the usage of specialized software, for which I have used the R packages survey(Lumley, n.d.) and lodown(Anthony Joseph Damico, n.d.). Each regression is the combination of 5 sub-regressions on each imputation replicate, with bootstrapped standard errors. They can easily take more than 3 days to complete on a powerful server. These regressions will be labelled by their standard errors, which is bootstrap. An alternative is to pool all the implicates together on a regular regression and then multiply the standard errors by $\sqrt{5}$, these regressions will be labelled as simple.

Loans with zero interest rates are excluded. They may be non-profit loans which are not bound to competitive forces. Loans given directly by the government or directly from government programs are also excluded. The terms of these loans are set annually according to regulations or budgets, and don't need to obey market forces. However loans related indirectly to government programs are included. For adjustable interest rate loans with more than one rate reported, I have used the one closer to loan origination. For analyzing implicit interest rates, I only included loans with reasonable implicit interest rates. That is, I filtered loans with an implicit interest rate between $0 \%$ and $50 \%$. Then I winsorized interest rates. 
Table 4: Summary Statistics for HMDA Data

Accross disaggregated groups

\begin{tabular}{lrrrrrrr}
\hline Variable & Mean & Quartile 1 & Median & Quartile 3 & Min & Max & SD \\
\hline Approval Rate & 0.72 & 0.59 & 0.71 & 0.85 & 0.00 & 1.00 & 0.20 \\
Origination Rate & 0.64 & 0.49 & 0.63 & 0.79 & 0.00 & 1.00 & 0.23 \\
Coapplicant & 0.50 & 0.36 & 0.53 & 0.64 & 0.00 & 1.00 & 0.18 \\
Adj. Income & 95237.30 & 64973.33 & 83971.28 & 108551.12 & 0.00 & 11136885.52 & 53744.51 \\
Adj. Amount & 164051.00 & 108022.13 & 148597.52 & 207092.41 & 933.62 & 25340612.15 & 100662.33 \\
\hline
\end{tabular}

Sample of individual loans

\begin{tabular}{lrrrrrrr}
\hline Variable & Mean & Quartile 1 & Median & Quartile 3 & Min & Max & SD \\
\hline Approval Rate & 0.72 & 0.00 & 1.00 & 1.00 & 0.00 & 1.00 & 0.45 \\
Origination Rate & 0.64 & 0.00 & 1.00 & 1.00 & 0.00 & 1.00 & 0.48 \\
Coapplicant & 0.49 & 0.00 & 0.00 & 1.00 & 0.00 & 1.00 & 0.50 \\
Adj. Income & 94442.66 & 43576.02 & 66900.02 & 104716.81 & 933.62 & 10789246.35 & 144996.05 \\
Adj. Amount & 165161.46 & 66899.22 & 123631.79 & 209354.36 & 933.62 & 19268179.74 & 182914.39 \\
\hline
\end{tabular}

Another important dataset for this study is the Loan Application Register(LAR) for HMDA loans published by FFIEC. It contains records of all mortgage applications subject to HMDA, with information about approval status, geographic area, demographics of the applicant, loan characteristic and regulatory agency. The reporting entity is individually identified but not the applicant. With this dataset I obtained the aggregated number of applications which I use to estimate credit demand, and the approval rates which I use to study credit supply of the consumer mortgage financial market. This dataset contains supplementary information about reporting lenders. The information includes the RSSD code, a unique identifier for each lending entity. I used bulk data from the Federal Reserve National Information Center to obtain the type of charter for each RSSD code. The FFIEC publishes census data which can be used to complement HMDA. Data was filtered to include only the 50 states and the district of Columbia.

I will use a small random sample of all the applications to analyze approval rates and I will use disaggregated statistics to study changes on the number of applications. Statistics of HMDA data were disaggregated by year of origination, charter, loan type, purpose, relative neighbour income level, occupancy of the property, government program relationship, state, type of property, type of lien, sex, race and ethnicity of the applicants. There are additional variables with information for each of these groups about average co-applicant status, pre-approval status, income and amount requested.

I have complemented the main datasets with other data. I used loan origination statistics published by CFPB to improve the precision on time of origination for the SCF dataset. Appendix B explains how this statistics were used. 
To make the amount loaned comparable across years, it had to be adjusted using the Consumer Price Index(CPI). I used the CPI for all urban consumers provided by the US Bureau of Labor Statistics using the year of 2010 as anchor point.

The Federal Reserve Board publishes many interesting statistics and datasets. Among the ones that I used are the constant maturity US Treasury yield curve and Moody's seasoned BAA corporate bond yield. These series were used to calculate the equivalent risk free or corporate interest rate of flexible loans for which the payment frequency or maturity was missing. If missing, maturity was assumed to be 20 years. Additionally, I constructed a standard measure of overall market risk premium assuming a maturity of 20 years.

Gürkaynak, Sack, and Wright (2007) published the time series of parameters needed to calculate the US Treasury zero coupon curve. I've used it to calculate the equivalent risk free interest rate of annuity-like loans in order to better take into account the effect of a declining principal. To calculate the equivalent corporate rate, I proceeded similarly and used the High Quality Market(HQM) corporate bond spot rate published by the US Department of the Treasury.

\subsection{Complexity of Loan Contracts}

The interest rate is not the only term of a loan that determines cost. Costs are also given by origination fees, finance fees, finance charges, post origination fees and penalties. These variables are not observable in the survey but most can be captured with the implicit interest rate. The implicit interest rate is simply the internal rate of return calculated from the loan amount, schedule of payments, regular payment amount and balloon amount. This variable has limitations, it doesn't capture non-amortized origination fees or penalties. Also, the implicit interest rate will be affected by anything that affects the consistency of the annuity formula. Implicit interest rate is just the combination of changes in interest rates and changes in the bias of the annuity formula. It increases as explicit interest rate increases and decreases as the bias of the annuity formula becomes negative.

Traditionally, loans were simple annuities. In the SCF of 1983, 99.1\% of loans with complete data are consistent with the annuity and balloon formula at a 1\% error rate. For this SCF of 2013, only 10.3\% of loans with complete data are consistent at the same error rate. This change reflects an increase in complexity of loan contracts, changes in the quality of survey data or both. For each loan I use deviations 
from the annuity formula to calculate a measure of bias, $I_{2}$, as explained in Appendix A. This bias measure should be symmetric and centered at zero for random errors. Positive values indicate that the amount loaned is higher than the present value of payments(including balloon) discounted at the loan interest rate, negative values indicate the opposite. The measure is bound between -1 and 1 . There are two important clusters in the SCF 2013 dataset that are clearly not centered at zero: mortgages with taxes or homeowner insurance bundled into payments and student loans. For student loans the cluster is positive and is composed of loans with higher amount or shorter maturity than the median. Therefore, control variables must include a variable indicating whether non-annuity concepts are included in payments and a different slope for amount and maturity of educational loans.
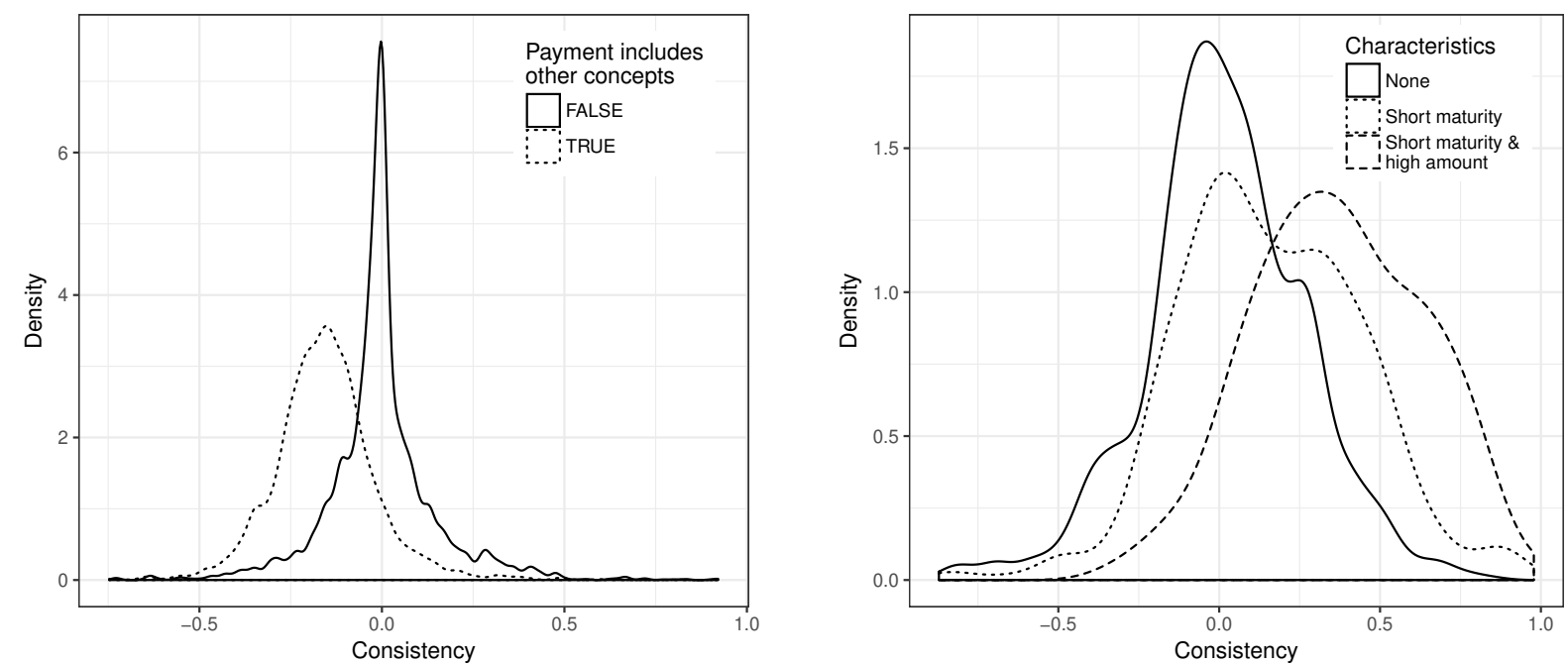

Figure 1: Bias with respect to annuity formula for mortgages(left) and student loans(right)

It's clear that the bias measure for mortgages is negative because taxes and homeowner insurance are included in reported payments, which inflate the present value of payments. What is not clear is the source of inconsistency for student loans. I will assume the main latent factor is the flexibility required by students, which is not correlated to regulatory changes.

I assume that the remaining variation in absolute bias captures changes in the complexity of loan contracts. This in turn affects the ability of lenders to hide costs, obfuscate information and overburden borrower's cognitive abilities. Also I assume that changes in this variable at the time of regulation stem directly from regulatory changes. 


\subsection{Calculate equivalent interest rates}

I calculated the equivalent risk free interest rate and the equivalent corporate interest rate for every loan. In principle this is not necessary. If the term structure of interest rates is constant, it's enough to control for maturity. However changes in the term structure of interest rates are problematic. For instance, there could be placebo regulatory change affecting a long-term loan category like mortgages. The inversion of the term structure would cause a decrease in mortgage interest rates in comparison to other short-term loan categories. This could be misattributed to regulatory effects. For the period considered here, the term structure is inverted briefly in 2007. I think it's good practice to control for equivalent interest rates. Also, controlling for these variables can increase precision.

It's tempting to use the interest rate of treasury securities or corporate bonds of a comparable maturity. This would ignore the fact that most consumer loans are annuities whereas treasury securities and corporate bonds usually have a constant principal amount. I constructed the schedule of payments for each loan with known maturity and payment frequency. At each of these payments, I discounted the payment amount at the spot rate for that maturity. For this I used the spot rates mentioned in the data section. The sum of the discounted quantities is equivalent to the present value of the loan.

$$
\mathrm{PV}(\text { payment amount, } n, T \text {, balloon }) \equiv \sum_{t=\frac{T}{n}}^{T}\left(\text { payment amount } \cdot \exp \left(-r_{t} \cdot t\right)\right)+\text { balloon } \cdot \exp \left(-r_{T} \cdot T\right)
$$

Then I proceeded to calculate the APR implied by that present value to obtain the equivalent annuity interest rate. I solved for the internal rate of return(IRR) using the secant method.

$$
\mathrm{PV}(\text { payment amount, } n, T, \text { balloon })=\frac{\text { payment amount }}{\exp (\mathrm{IRR})-1} \cdot(1-\exp (-\mathrm{IRR} \cdot T))+\text { balloon } \cdot \exp (-\mathrm{IRR} \cdot T)
$$

There were loans without a known schedule of payments. Most of them were student loans that provided a more flexible form of credit. For these, the equivalent risk free or corporate interest rate is just the interpolated constant-maturity interest rate at the maturity of the loan. Interest rates on bonds are usually quoted on semi-annual bond basis(SABB). I standardized interest rates to continuously compounded rates. 
Only at the final step they were converted to annual percentage rates(APR) which is an annual nominal rate.

\section{Research Design}

The objective of this study is to identify the effects of consumer financial protection regulation on market equilibrium loan terms and evaluate the hypotheses made above. A representative sample of the transactions are observable, which is the SCF dataset. This research design is similar to that of Stango and Zinman (2011). The data used in the regressions spans the period between 2005 and 2013.

The first dependent variable that I will use to measure loan cost is interest rate. Consumer loans have become increasingly complex and they may contain other costs in the form of fees. To capture these other costs I will build another variable, implicit interest rate, and use it as a dependent variable. These rates are APR, nominal annual rates. These variables are winsorized at $1 \%$. The last variable that I will analyze is annuity formula bias, which is the measure $I_{2}$ in Appendix A. I assume that increasing absolute(bias) proxies for increasing contract complexity.

The goal of these variables is to capture credit cost. The bulk of credit costs is captured by the implicit interest rate. However there are two types of fees that are not captured by this measure, non-amortized origination fees and contingent fees. For most loans these fees are not an issue. Non-amortized fees paid at origination are important for mortgages, specially to regulatory changes like MDIA or RESPA08 that include settlement cost disclosures. The analysis should take into account that there is a non-observable component in the cost of mortgages. For other regulatory changes, the impact of non-amortized fees paid at origination is limited. Borrowers are in need of money and their ability to pay fees is constrained. Large fees have to be amortized.

I will use diffs-in-diffs regressions to study what are the changes that different regulations have on the dependent variables. The variables of interest are the probability that a regulation is in effect at loan origination interacted with the characteristics of loans subject to that regulatory change. Sub-interactions are left as controls but are not shown on the tables. Some of the interactions or sub-interactions could not be estimated. For instance, flexible loans can't be included in regressions of implicit interest rate or bias because the variables can't be calculated. 


$$
\begin{aligned}
& \text { Dependent }_{i}=\sum_{r=1}^{R} \beta_{r} \cdot \operatorname{Pr}\left(\text { Orig. after Regulation }{ }_{r, i}\right) \cdot \text { Characteristic Subject to Regulation }_{r, i}
\end{aligned}
$$

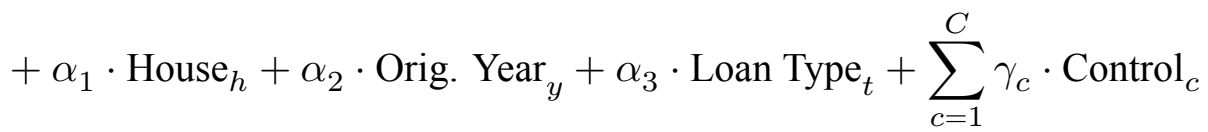

Control variables include household and year of origination dummies, loan type, loan purpose, loan characteristics, equivalent interest rates, market risk premium and a dummy for the provisions of Helping Families Save Their Homes Act. The equivalent rates are the equivalent risk free APR and the corporate APR for an annuity with the same payment schedule. Loan characteristics include charter/type of institution, flexibility, $\log$ (maturity), adjustable rate dummy, $\log$ (amount) adjusted by CPI, private mortgage insurance dummy, refinance dummies, government program relation dummy, dummies indicating that payments include non-annuity concepts like homeowners insurance and a dummy to indicate first time home purchase loans. Additionally, I control for the interaction of educational loan dummy with $\log$ (maturity) and $\log$ (amount) in the regressions of bias or implicit interest rate. Control variables are not shown on tables. A key control is household fixed effects. I assume that idiosyncratic credit risk, financial sophistication and the location of families are stable across time, and are therefore captured by household fixed effects.

The variable GovRel only captures whether the first mortgage secured by the consumer's main dwelling is related to any federal government program. However there are many federal related mortgages that escape the reach of this variable. First, all mortgages secured by a consumer's secondary dwelling and some mortgages secured by a consumer's main dwelling are not included. Second, panelists may not be aware that their mortgage is federally related. Third, even if the mortgage was not federally related at origination, the mortgage originator may want to allow for that possibility in a future. In order to sell the mortgage to government sponsored enterprises like Fannie Mae or Freddie Mac, the loan must have complied with the requirements that other federal related loans had at origination. A regulatory change that affects federally related mortgages will affect for sure GovRel mortgages. Many non GovRel mortgages will also be affected, but not all of them which will probably underestimate the effect of regulation. It's important to keep this in mind when evaluating the results of regressions.

The diffs-in-diffs design uses differences between loan types excludes affected by different regulations to identify their effects. The identification of this effect is therefore not contaminated by general government programs introduced after the financial crisis of 2007-2008 to influence the credit market. Controlling 
for equivalent risk free and corporate interest rates should capture government intervention in the credit market.

Lastly, I will analyze HMDA data during the same time period. With a small random sample I will build a diffs-in-diffs logistic regression on approval rates. I will use disaggregated statistics on all applications to build a weighted least squares regression on the logarithm of applications. The variables of interest are again the probability that a regulation is in effect at loan origination interacted with the characteristics of loans subject to that regulatory change

The control variables include year dummies, state dummies, type/charter of the institution, occupancy of the property and characteristics of the applicant and the loan. The characteristics of the applicant are sex, race, ethnicity and income, adjusted by CPI. The characteristics of the loan are the type of loan, purpose, pre-approval request, co-applicant existence, type of lien and amount loaned, adjusted by CPI. It's not possible to know which applications were made by the same individual. Unfortunately the HMDA dataset doesn't contain information about credit risk of the applicant, financial sophistication of the applicant, credit costs or the terms of the loans other than the amount loaned. Controlling for income should partially control for credit risk. However, the lack of information about credit cost may pose important limitations. It's also important to control for the effect migratory movements on the number of applications. The regression on the logarithm of applications includes additional controls. These are the logarithm of state population for the same racial and ethnic group, and for the same sex group. Also in the regression on number of applications, each disaggregated statistic group is weighted by the average number of applications across years.

For the HMDA dataset the variable GovRel has wider coverage. It captures loans originated under government programs as well as loans later sold to government sponsored enterprises. It is defined for all mortgages and the information is provided by the loan originator, not the borrower. 


\section{Main Results}

Table 5: Main Regressions on Credit Cost and Annuity Bias

\begin{tabular}{|c|c|c|c|c|}
\hline & Int & Imp Int & Bias & abs(Bias) \\
\hline MDIA : AnyMortgage & $\begin{array}{l}-15.618 \\
(35.020)\end{array}$ & $\begin{array}{l}-35.380 \\
(63.765)\end{array}$ & $\begin{array}{c}0.197 \\
(1.317)\end{array}$ & $\begin{array}{c}1.445 \\
(1.049)\end{array}$ \\
\hline MDIA : NewCoverMDIA & $\begin{array}{c}7.346 \\
(23.676)\end{array}$ & $\begin{array}{c}29.908 \\
(37.083)\end{array}$ & $\begin{array}{l}-0.059 \\
(0.798)\end{array}$ & $\begin{array}{l}-0.658 \\
(0.636)\end{array}$ \\
\hline HOEPA08 : AnyMortgage & $\begin{array}{c}14.548 \\
(31.418)\end{array}$ & $\begin{array}{c}9.969 \\
(64.310)\end{array}$ & $\begin{array}{l}-0.229 \\
(1.306)\end{array}$ & $\begin{array}{l}-1.354 \\
(1.041)\end{array}$ \\
\hline HOEPA08 : MainMortgage & $\begin{array}{c}0.235 \\
(3.700)\end{array}$ & $\begin{array}{c}1.592 \\
(7.335)\end{array}$ & $\begin{array}{c}0.241 \\
(0.147)\end{array}$ & $\begin{array}{c}0.107 \\
(0.117)\end{array}$ \\
\hline HOEPA08 : NewHome & $\begin{array}{c}0.393 \\
(2.448)\end{array}$ & $\begin{array}{l}-0.244 \\
(5.783)\end{array}$ & $\begin{array}{c}0.160 \\
(0.114)\end{array}$ & $\begin{array}{c}0.036 \\
(0.091)\end{array}$ \\
\hline HOEPA08 : NewHome : MainMortgage & $\begin{array}{c}6.934 \\
(23.827)\end{array}$ & $\begin{array}{c}26.534 \\
(37.854)\end{array}$ & $\begin{array}{l}-0.273 \\
(0.813)\end{array}$ & $\begin{array}{l}-0.729 \\
(0.648)\end{array}$ \\
\hline RESPA08 : AnyMortgage & $\begin{array}{c}-6.988 \\
(14.131)\end{array}$ & $\begin{array}{c}-6.953 \\
(28.759)\end{array}$ & $\begin{array}{l}-0.011 \\
(0.586)\end{array}$ & $\begin{array}{c}0.517 \\
(0.467)\end{array}$ \\
\hline RESPA08 : GovRel & $\begin{array}{l}-0.099 \\
(0.702)\end{array}$ & $\begin{array}{l}-0.246 \\
(1.189)\end{array}$ & $\begin{array}{l}-0.030 \\
(0.023)\end{array}$ & $\begin{array}{l}0.037 * * \\
(0.019)\end{array}$ \\
\hline HEOAPEL : EduLoan & $\begin{array}{l}-0.503 \\
(1.095)\end{array}$ & $\begin{array}{c}9.097 * * * \\
(2.113)\end{array}$ & $\begin{array}{l}-0.020 \\
(0.039)\end{array}$ & $\begin{array}{c}0.023 \\
(0.031)\end{array}$ \\
\hline HEOAPEL : NoFlex & $\begin{array}{l}-1.099 \\
(0.829)\end{array}$ & & & \\
\hline HEOAPEL : EduLoan : NoFlex & $\begin{array}{c}2.778 \text { *** } \\
(0.841)\end{array}$ & & & \\
\hline MDIA2 : AdjMortgage & $\begin{array}{c}0.649 \\
(0.828)\end{array}$ & $\begin{array}{c}0.380 \\
(1.396)\end{array}$ & $\begin{array}{l}-0.028 \\
(0.028)\end{array}$ & $\begin{array}{l}-0.004 \\
(0.022)\end{array}$ \\
\hline MDIA2 : GovRel & $\begin{array}{l}-1.131 \\
(0.697)\end{array}$ & $\begin{array}{l}-0.712 \\
(1.191)\end{array}$ & $\begin{array}{c}0.013 \\
(0.023)\end{array}$ & $\begin{array}{l}-0.024 \\
(0.019)\end{array}$ \\
\hline MDIA2 : AdjMortgage : GovRel & $\begin{array}{c}-4.525 * * * \\
(1.707)\end{array}$ & $\begin{array}{c}1.373 \\
(2.820)\end{array}$ & $\begin{array}{c}0.091 \\
(0.057)\end{array}$ & $\begin{array}{l}-0.029 \\
(0.045)\end{array}$ \\
\hline CompBan : OtherMortgage & $\begin{array}{c}0.331 \\
(0.917)\end{array}$ & $\begin{array}{c}0.980 \\
(1.531)\end{array}$ & $\begin{array}{l}-0.015 \\
(0.030)\end{array}$ & $\begin{array}{l}-0.001 \\
(0.024)\end{array}$ \\
\hline SAFE : AnyMortgage & $\begin{array}{c}0.010 \\
(0.547)\end{array}$ & $\begin{array}{c}1.103 \\
(0.999)\end{array}$ & $\begin{array}{c}-0.036 * \\
(0.019)\end{array}$ & $\begin{array}{c}0.021 \\
(0.015)\end{array}$ \\
\hline AdRuleFTC : FTCMortgage & $\begin{array}{c}0.052 \\
(0.449)\end{array}$ & $\begin{array}{c}-1.523 * * \\
(0.744)\end{array}$ & $\begin{array}{c}0.013 \\
(0.015)\end{array}$ & $\begin{array}{l}-0.018 \\
(0.012)\end{array}$ \\
\hline HEOACalc : EduLoan & $\begin{array}{l}-0.002 \\
(0.920)\end{array}$ & $\begin{array}{l}-3.554 \\
(2.359)\end{array}$ & $\begin{array}{l}-0.021 \\
(0.040)\end{array}$ & $\begin{array}{c}0.028 \\
(0.032)\end{array}$ \\
\hline HEOACalc : EduInst & $\begin{array}{c}-2.383 * \\
(1.353) \\
\end{array}$ & $\begin{array}{c}-13.779 * * \\
(6.021) \\
\end{array}$ & $\begin{array}{c}-0.214 * * \\
(0.097) \\
\end{array}$ & $\begin{array}{c}-0.341 * * * \\
(0.078) \\
\end{array}$ \\
\hline $\begin{array}{l}\mathrm{N} \\
\text { Std. Errors }\end{array}$ & $\begin{array}{c}5698 \\
\text { Simple }\end{array}$ & $\begin{array}{c}4148 \\
\text { Simple }\end{array}$ & $\begin{array}{c}4951 \\
\text { Simple }\end{array}$ & $\begin{array}{c}4951 \\
\text { Simple }\end{array}$ \\
\hline
\end{tabular}

*** $\mathrm{p}<0.01 ; * * \mathrm{p}<0.05 ; * \mathrm{p}<0.1$. 
Table 6: Main Regressions Bootstraped

\begin{tabular}{|c|c|c|c|c|}
\hline \multirow{3}{*}{ MDIA : AnyMortgage } & Int & Imp Int & Bias & abs(Bias) \\
\hline & -28.539 & -32.348 & 0.094 & $1.757 * *$ \\
\hline & (48.129) & $(44.528)$ & $(0.928)$ & $(0.544)$ \\
\hline \multirow[t]{2}{*}{ MDIA : NewCoverMDIA } & 12.056 & 28.018 & -0.052 & $-0.765 * *$ \\
\hline & $(18.663)$ & $(17.694)$ & $(0.376)$ & $(0.178)$ \\
\hline \multirow[t]{2}{*}{ HOEPA08 : AnyMortgage } & 29.910 & 9.040 & -0.087 & $-1.754 * *$ \\
\hline & $(57.186)$ & $(64.278)$ & $(1.065)$ & $(0.615)$ \\
\hline \multirow{2}{*}{ HOEPA08 : MainMortgage } & 0.118 & 0.870 & $0.246 *$ & 0.106 \\
\hline & $(1.403)$ & $(9.938)$ & $(0.090)$ & $(0.113)$ \\
\hline \multirow[t]{2}{*}{ HOEPA08 : NewHome } & 0.708 & -1.360 & $0.179 * *$ & 0.034 \\
\hline & $(1.010)$ & $(10.176)$ & $(0.052)$ & $(0.097)$ \\
\hline \multirow[t]{2}{*}{ HOEPA08 : MainMortgage : NewHome } & 11.276 & 25.512 & -0.281 & $-0.834 * * *$ \\
\hline & $(18.573)$ & $(25.024)$ & $(0.416)$ & $(0.159)$ \\
\hline \multirow[t]{2}{*}{ RESPA08 : AnyMortgage } & -14.474 & -5.838 & -0.071 & $0.714 *$ \\
\hline & $(26.834)$ & $(26.092)$ & $(0.435)$ & $(0.277)$ \\
\hline \multirow[t]{2}{*}{ RESPA08 : GovRel } & -0.113 & -0.331 & $-0.030 * *$ & $0.035 * *$ \\
\hline & $(0.689)$ & $(0.457)$ & $(0.008)$ & $(0.012)$ \\
\hline \multirow[t]{2}{*}{ HEOAPEL : EduLoan } & -0.359 & $10.803 * *$ & -0.029 & 0.020 \\
\hline & $(1.335)$ & $(2.800)$ & $(0.060)$ & $(0.041)$ \\
\hline \multirow[t]{2}{*}{ HEOAPEL : NoFlex } & -1.098 & & & \\
\hline & $(1.376)$ & & & \\
\hline \multirow[t]{2}{*}{ HEOAPEL : EduLoan : NoFlex } & 2.679 & & & \\
\hline & $(1.542)$ & & & \\
\hline \multirow[t]{2}{*}{ MDIA2 : AdjMortgage } & $0.761 * *$ & 0.027 & -0.026 & -0.005 \\
\hline & $(0.179)$ & $(0.755)$ & $(0.014)$ & $(0.015)$ \\
\hline \multirow[t]{2}{*}{ MDIA2 : GovRel } & -1.147 & -0.933 & 0.014 & $-0.025 *$ \\
\hline & $(0.600)$ & $(0.631)$ & $(0.009)$ & $(0.011)$ \\
\hline \multirow[t]{2}{*}{ MDIA2 : AdjMortgage : GovRel } & $-5.071 * *$ & 2.325 & $0.113 *$ & -0.041 \\
\hline & $(1.138)$ & $(1.868)$ & $(0.053)$ & $(0.041)$ \\
\hline \multirow[t]{2}{*}{ CompBan : OtherMortgage } & 0.278 & 0.880 & -0.017 & -0.006 \\
\hline & $(0.162)$ & $(0.898)$ & $(0.013)$ & $(0.015)$ \\
\hline \multirow[t]{2}{*}{ SAFE : AnyMortgage } & 0.137 & 1.518 & $-0.036 *$ & $0.024 *$ \\
\hline & $(0.723)$ & $(1.149)$ & $(0.015)$ & $(0.010)$ \\
\hline \multirow[t]{2}{*}{ AdRuleFTC : FTCMortgage } & 0.040 & $-1.718 * *$ & $0.013 *$ & -0.017 \\
\hline & $(0.100)$ & $(0.461)$ & $(0.005)$ & $(0.009)$ \\
\hline \multirow[t]{2}{*}{ HEOACalc : EduLoan } & -0.024 & -5.123 & -0.025 & 0.036 \\
\hline & $(0.825)$ & $(4.863)$ & $(0.092)$ & $(0.064)$ \\
\hline \multirow[t]{2}{*}{ HEOACalc : EduInst } & -2.287 & & -0.238 & -0.341 \\
\hline & $(1.284)$ & & $(0.197)$ & $(0.161)$ \\
\hline Std. Errors & Bootstrap & Bootstrap & Bootstrap & Bootstrap \\
\hline
\end{tabular}

There are two regression tables. Table 5 was obtained from a simple weighted least squares regression including all implicates and had the standard errors multiplied by $\sqrt{5}$. Table 6 was obtained taking into account the structure of survey data and standard errors were obtained using the replicate weights. The dependent variables are (explicit) interest rate, implicit interest rate, $I_{2}$ bias measure and absolute bias measure. First I will discuss the hypotheses for which I found significant results. 
There is support for the effectiveness of alternative hypothesis 9 about the FTC advertising rule. It consisted on giving the FTC authority and proper incentives to go after deceiving lenders. The estimated change and standard error in explicit interest rate are very close to zero. Implicit interest rates decline significantly for mortgages regulated by the FTC at the time of regulation. This scenario, with a decrease in implicit but not explicit interest rates, is plausible. Before regulation, deceiving lenders could advertise mortgages at competitive explicit costs and shroud certain costs to obtain a profit. After the FTC enforced the rule, they would be deprived of the shrouding mechanism. I believe the effectiveness of this rule shows that deception was happening at the marketplace, since this rule aimed to curve deception.

Evidence contradicts alternative hypothesis 6 about HEOA private education loans. Implicit interest rates of education loans increase at the time of the regulation. This effect is high in magnitude and significant. Explicit interest rates of non-flexible education loans drop at the same time, but it is significant only for simple SE. PEL provisions only affect closed end loans, which are proxied by NoFlex.

Before using contradictory results as evidence against the alternative hypotheses, it must be clear that the results are not compatible with the scenario of effective regulation. At first sight, the scenario of effective regulation after unshrouding in the add-on model might offer an explanation for these results. Even though unshrouding should diminish real credit costs, it can increase reported explicit interest rate. Lenders would have limitations to use hidden fees and these fees would be less effective due to disclosures. Lenders could then take away hidden fees and move some subsidized costs into explicit interest rates.

However this scenario is unlikely. The reason is that the bulk of credit costs is that total credit costs, as proxied by implicit interest rate increase. I argue that the bulk of credit costs is captured by implicit interest rate, and therefore it proxies for total credit costs. There are two types of fees that are not captured by this measure, non-amortized origination fees and contingent fees. Non-amortized fees paid at origination can not be large in comparison to the amount loaned because borrowers are in need of money. Large fees have to be amortized. As for contingent fees, they depend on the frequency in which borrowers step on them. These irregular fees are not as useful as mandatory fees for substituting regular interest rate payments. Also, the size and conditions of these fees are constrained by existing regulation. Contrary to credit cards, late student loan payments rarely trigger a penalty APR. Overall, it's difficult that a marked decrease in implicit interest rate could be compensated by an increase in those other fees, let alone surpassed.

I will conjecture about this failure. One outstanding point of PEL provisions is the extraordinary com- 
plexity of the loan process. Students that apply for a loan must obtain a self-certification form provided by the educational institution before loan consummation. It's not unreasonable for lenders to incur high costs in order to process this additional paperwork, and it's not unreasonable either that these costs are passed on to students. This extra hassle can also place a burden on students and discourage them from seeking credit.

I will now discuss the hypotheses for which I didn’t find significant results.

There is no evidence in favor of alternative hypothesis 2 about MDIA. The interaction with AnyMortgage captures the difference between the old RESPA disclosures and the new MDIA ones. The estimated change is a decrease in borrowing costs, although it's not significant. Absolute bias on the annuity formula increases, which indicates higher contract complexity. The interaction with NewCoverMDIA captures the difference between RESPA disclosures and no disclosure. This is associated with a non-significant increase in borrowing costs and a significant decrease in contract complexity.

Alternative hypothesis 1 about 2008 HOEPA rule is not backed by evidence. The interaction with AnyMortgage captures the effect of advertising provisions, which are only associated with a significant decrease in contract complexity. The interaction with MainMortgage captures the difference between the effect of the new HOEPA provisions and the old ones. The effect that I consider is the effect of HOEPA provisions on all loans newly covered by HOEPA, regardless of whether they trigger the high-cost threshold. Trespassing the high-cost threshold is an endogenous decision. On the other hand, I assume that the change in HOEPA regulatory provisions and coverage is exogenous to market agents. The double interaction with NewHome:MainMortgage captures the effect of old HOEPA provisions. It's only associated with a decrease in contract complexity.

Alternative hypothesis 4 about RESPA08 is not backed by evidence. Borrowing costs decrease for all mortgages, but the change is insignificant. Contract complexity, as measured by absolute deviation from annuity formula, increases significantly.

Previously I explained the limitations of implicit interest rate. It can't capture non-amortized settlement costs, which is an important component of MDIA and RESPA08 disclosures. This may explain the lack of significant results for these regulations.

Alternative hypothesis 3 about MDIA2 is difficult to evaluate. Explicit interest rate for adjustable mortgages related to government programs decreases significantly. Implicit interest rate increases but this 
effect is not significantly different from 0 . There is the possibility that these disclosures have turned adjustable mortgages into inferior products. After these disclosures, borrowers may see adjustable mortgages much less attractive than fixed mortgages. At the demanded price, the market for adjustable mortgages would disappear. Deception can thrive in this scenario, lenders are incentivized to lower explicit costs and increase shrouded costs.

There are reasons to justify why the effects of MDIA2 can be captured by the dependent variables. This disclosure is not focused on settlement costs, it warns about the risks of floating rate mortgages. This can reduce demand which lowers credit costs of floating rate mortgages. To entice demand this discount should be made noticeable, interest rates have to diminish.

There is no evidence to support alternative hypothesis 5 about CompBan. This regulation extended the ban on compensation practices to secondary mortgages but there is no significant effect on explicit or implicit interest rate. This result is not a surprise, the rule banned compensation based on terms other than the amount loaned. The monopolistic lenders of Inderst and Ottaviani (2012) can still compensate brokers. They can do it as long as this compensation is fixed or proportional to the amount loaned.

Alternative hypothesis 8 about licensing of mortgage originators is not backed by evidence either.

There is not enough support for alternative hypothesis 7 about the effectiveness of HEOA online calculator. Explicit and implicit interest rate decrease, but the change is not significant in the bootstrapped regression. Perhaps the sample size is small, it's plausible that both credit costs and contract complexity decrease. The first reason is that informing students about grants and federal programs increases competition in the credit market. The second one is that it increases comparability of university offerings. Students can better compare total education costs, which includes financing, and this facilitates competition. Contrary to PEL provisions, this rule probably doesn't place such a high burden on education institutions or students. The online calculator enjoys a high level of scalability that paperwork processing can't ever reach. 


\section{Additional Results}

Table 7: Supply and Demand Regressions

\begin{tabular}{|c|c|c|c|c|}
\hline & Approved & $\log$ (Applications) & Approved & $\log$ (Applications) \\
\hline MDIA : GovRel & $\begin{array}{c}-0.383 * * * \\
(0.091)\end{array}$ & $\begin{array}{c}3.201 * * * \\
(0.034)\end{array}$ & $\begin{array}{c}-0.383 * * \\
(0.158)\end{array}$ & $\begin{array}{c}3.201 * * * \\
(0.596)\end{array}$ \\
\hline MDIA : NewCoverMDIA & $\begin{array}{l}-0.165 \\
(0.155)\end{array}$ & $\begin{array}{c}3.114 * * * \\
(0.073)\end{array}$ & $\begin{array}{l}-0.165 \\
(0.279)\end{array}$ & $\begin{array}{c}3.114 * * * \\
(0.539)\end{array}$ \\
\hline MDIA : GovRel : NewCoverMDIA & $\begin{array}{c}-0.285 * * * \\
(0.055)\end{array}$ & $\begin{array}{c}0.413 * * * \\
(0.018)\end{array}$ & $\begin{array}{l}-0.285 \\
(0.191)\end{array}$ & $\begin{array}{c}0.413 * * * \\
(0.091)\end{array}$ \\
\hline HOEPA08 : MainMortgage & $\begin{array}{l}-0.086 \\
(0.141)\end{array}$ & $\begin{array}{c}-0.866 * * * \\
(0.061)\end{array}$ & $\begin{array}{l}-0.086 \\
(\mathrm{NaN})\end{array}$ & $\begin{array}{c}-0.866 * * * \\
(0.072)\end{array}$ \\
\hline HOEPA08 : NewHome & $\begin{array}{c}0.477 * * * \\
(0.058)\end{array}$ & $\begin{array}{c}-0.688 * * * \\
(0.025)\end{array}$ & $\begin{array}{c}0.477 * * * \\
(0.037)\end{array}$ & $\begin{array}{c}-0.688 * * * \\
(0.138)\end{array}$ \\
\hline HOEPA08 : MainMortgage : NewHome & $\begin{array}{c}-0.779 * * * \\
(0.161)\end{array}$ & $\begin{array}{c}3.492 * * * \\
(0.075)\end{array}$ & $\begin{array}{c}-0.779 * * * \\
(0.273)\end{array}$ & $\begin{array}{c}3.492 * * * \\
(0.518)\end{array}$ \\
\hline RESPA08 : GovRel & $\begin{array}{c}0.256 * * * \\
(0.083)\end{array}$ & $\begin{array}{c}-2.194 * * * \\
(0.032)\end{array}$ & $\begin{array}{l}0.256 * * \\
(0.100)\end{array}$ & $\begin{array}{c}-2.194 * * * \\
(0.322)\end{array}$ \\
\hline MDIA2 : GovRel & $\begin{array}{l}-0.010 \\
(0.039)\end{array}$ & $\begin{array}{c}0.148 * * * \\
(0.014)\end{array}$ & $\begin{array}{c}-0.010 \\
(\mathrm{NaN})\end{array}$ & $\begin{array}{c}0.148 * * * \\
(0.032)\end{array}$ \\
\hline CompBan : OtherMortgage & $\begin{array}{l}-0.021 \\
(0.055)\end{array}$ & $\begin{array}{c}0.123 * * * \\
(0.022)\end{array}$ & $\begin{array}{l}-0.021 \\
(0.069)\end{array}$ & $\begin{array}{c}0.123 * * * \\
(0.038)\end{array}$ \\
\hline AdRuleFTC : FTCMortgage & $\begin{array}{c}1.291 * * * \\
(0.039)\end{array}$ & $\begin{array}{c}0.063 * * * \\
(0.016) \\
\end{array}$ & $\begin{array}{c}1.291 * * * \\
(0.236) \\
\end{array}$ & $\begin{array}{r}0.063 \\
(0.232) \\
\end{array}$ \\
\hline $\mathrm{N}$ & 442482 & 390969 & & \\
\hline Model & Logit & WLS & Logit & WLS \\
\hline Std. Errors & Simple & Simple & Double Cluster & Double Cluster \\
\hline
\end{tabular}

$* * * \mathrm{p}<0.01 ; * * \mathrm{p}<0.05 ; * \mathrm{p}<0.1$

This section studies how different regulations affect credit supply and demand during the years 2005 to 2013 using HMDA data. Approval rate is a proxy for credit supply and the logarithm of the number of applications is a proxy for credit demand. The regression of $\log$ (Applications) uses only groups with complete time series, that is, there is one or more applications for each possible year of study. Among other entities, FTCMortgage includes lenders without known RSSD code.

The main purpose of this section is to be a robustness test. Only regulation affecting a subset of mortgage loans can be tested, which excludes HEOA provisions, SAFE licensing regulation and minor provisions of other rules.

Credit supply increased significantly after the FTC advertising rule for covered mortgages. The increase in credit demand is of smaller magnitude and not significant. All results indicate that the FTC advertising rule was effective.

Previously, MDIA2 regulation was associated with lower explicit credit costs on adjustable rate RESPA 
mortgages. In this dataset is not possible to tell apart adjustable rate applications from fixes rate applications. MDIA2 is just associated to higher demand of government related mortgages, which are covered by RESPA.

For other regulations, I will briefly discuss the results. There is a significant decrease in the approval rates following MDIA and HOEPAO8. This implies a decrease in credit supply which is inconsistent with relevant and effective regulation against market power, artificial complexity, obfuscation, deception, or agency conflicts. The decrease associated to HOEPAO8 is robust to double clustering. Regarding RESPA08, the coefficients show a significant increase in credit supply and a significant decrease in the number of applications. This scenario is consistent with regulation effectively unshrouding actual credit cost.

\section{Conclusions}

After all the regulatory changes introduced to protect consumers in financial markets, I only managed to obtain significant results for three regulatory changes. Only one of them, the FTC advertising rule of 2011, lowered credit costs without diminishing credit availability. HOEPA rule of 2008 is not effective, it is associated with a drop in credit supply. HEOA provisions about private education loans are associated with higher credit costs which is incompatible with effectiveness. Although not significant, evidence is consistent with effectiveness of HEOA online calculator provisions. The results for RESPA rule of 2008 are compatible with pre-regulation deception at the credit market. Further research is needed.

Results show that consumer financial protection can have a wide range of results. Regulation can help consumers as well as impose additional costs. Regulatory changes can have unintended side effects, even if they seem theoretically effective. This shifts the discussion to the rulemaking process. When evaluating the introduction of new regulation, rulemakers should take into account the potential benefits as well as the potential costs introduced, and consider deviations from the predicted scenario.

Regarding data, both the Survey of Consumer Finances and HMDA LAR are interesting datasets for studying consumer financial protection regulation. The SCF dataset requires careful inspection and understanding. Complexity can be managed with existing tools. The most important limitation for the SCF is the inability to capture some credit costs such as non-amortized origination and contingent fees, while 
for the HMDA LAR is the inability to capture credit costs at all. External datasets can be used as complements. In the end, both datasets are suitable for a detailed diffs-in-diffs analysis. 


\section{Appendix}

\section{Appendix A: Bias Measure}

I have considered two measures to asses the degree of loan consistency with the annuity formula(including balloon payment). Both are built upon $M$, the ratio of amount borrowed to present value of payments. In the equation below $r$ is the interest rate and $T$ is the maturity of the loan. Numerator and denominator are strictly positive quantities so the measure is always defined and positive. The ratio can produce numbers from 0 to $\infty$ and $M=1$ for loans consistent with the annuity formula.

$$
M=\frac{\text { Amount }}{\frac{\text { Payment }}{(\exp (r)-1)} \cdot(1-\exp (-r \cdot T))+\text { Balloon } \cdot \exp (-r \cdot T)}
$$

A problem of using $M$ in a regression is that the magnitude of the measure is clearly asymmetric around the unbiased point, $M=1$. The measure can range from 1 to $\infty$ when the amount is higher than the present value of payments, but it can only range from 0 to 1 in the opposite case.

The first bias measure is $I_{1}=\log (M)$ and has some desirable properties. This measure is 0 when the loan is consistent with the annuity formula as illustrated in equation 1. From equation 2 it can be seen that the magnitude of the measure is symmetric with respect to the numerator and denominator of $M$. The range extends from $-\infty$ to $\infty$ and is defined for all $M>0$. It's trivial to see that the measure is monotonic on $M$.

$$
\begin{gathered}
I_{1}(1)=\log (1)=0 \\
I_{1}\left(\frac{x}{y}\right)=\log \left(\frac{x}{y}\right)=-\log \left(\frac{y}{x}\right)=-I_{1}\left(\frac{y}{x}\right)
\end{gathered}
$$

The second bias measure is $I_{2}(M)=2 \cdot\left(M^{-1}+1\right)^{-1}-1$. It has the properties of $I_{1}$, the measure is 0 when the loan is consistent with the annuity formula(3) and the magnitude of the measure is symmetric(4) with respect to the numerator and denominator of $M$. However the range of this measure is finite, $I_{2}$ ranges from -1 to 1 , and is defined for all $M>0$. The measure is monotonic on $M$ as shown in equation 5 . 


$$
\begin{gathered}
I_{2}(M)=2 \cdot\left(M^{-1}+1\right)^{-1}-1=\frac{1-M^{-1}}{M^{-1}+1} \\
I_{2}(1)=2 \cdot \frac{1}{2}-1=0 \\
I_{2}\left(\frac{x}{y}\right)=\frac{1-\left(\frac{x}{y}\right)^{-1}}{\left(\frac{x}{y}\right)^{-1}+1}=\frac{\frac{x}{y}}{\frac{x}{y}} \cdot \frac{1-\left(\frac{x}{y}\right)^{-1}}{\left(\frac{x}{y}\right)^{-1}+1}=\frac{\frac{x}{y}-1}{\left(\frac{x}{y}\right)+1}=-\frac{1-\frac{x}{y}}{\left(\frac{x}{y}\right)+1}=-I_{2}\left(\left(\frac{x}{y}\right)^{-1}\right) \\
\frac{\partial I_{2}(M)}{\partial M}=2 \cdot\left(M^{-1}+1\right)^{-2} \cdot M^{-2}>0 \quad \forall M \neq 0
\end{gathered}
$$

$I_{2}$ is the measure I have chosen to use in the regressions and other parts of this study. 


\section{Appendix B: Improving precision of regulatory changes}

A problem of recent SCF datasets is that only the year of loan origination is public, but not the month. The precision of the time of origination is reduced twelvefold in a variable that is important to identify the effect of regulation. It's possible to partially counteract this effect by estimating the probability that the loan is originated after a certain date using external data and loan characteristics. The CFPB publishes monthly loan origination volume for mortgages, credit cards, automotive loans and education loans. The series are disaggregated according by either age of the borrower, credit score or relative neighbourhood income.

I used monthly loan originated volume over total yearly volume for a particular loan type and age cohort to estimate the probability that a loan was originated in a given month ${ }^{1}$. The purpose is to estimate the probability that loan origination occurs after the regulatory change. I used age cohort since the age of the household head is already given and it's trivial to compute the age of the household head at loan origination. For loan types not related to CFPB statistic categories I've used the sum of all non-revolving loan origination volume.

$$
\begin{aligned}
& \operatorname{Pr}\left(\text { origDate }_{l, a} \geq \operatorname{regDate} \mid \operatorname{vol}_{l, a}\right)=\frac{\left(1-\frac{\text { day }(\text { regDate })-1}{\text { dayslnMonth }(\text { regDate })}\right) \cdot \operatorname{vol}_{l, a}\left(\text { year }_{i}, \text { month }(\text { regDate })\right)}{\sum_{j=1}^{12} \operatorname{vol}_{l, a}\left(\text { year }_{i}, \text { month }_{j}\right)} \\
& +\frac{\sum_{j=1}^{\text {month }(\text { regDate })-1} \operatorname{vol}_{l, a}\left(\text { year }_{i}, \text { month }_{j}\right)}{\sum_{j=1}^{12} \operatorname{vol}_{l, a}\left(\text { year }_{i}, \text { month }_{j}\right)}
\end{aligned}
$$

To be slightly more precise, I interpolated monthly volume to daily volume using spline. A challenge of using this approach is that there is a restriction. The sum of daily origination volume over a month must be equal to the volume of originations for that month from the original series. For that end I first transformed the monthly volume of originations into cumulative volume, interpolated the data and transformed the interpolated cumulative volume back into periodic daily volume. This procedure satisfies the restriction. The resulting probabilities are very similar.

In order to estimate the effect of regulations more precisely, the more variation across cohorts the better. From the table above it can be seen that the standard deviation of intra-year probabilities is moderate. The average standard deviation within loan types is much smaller. Also, I use the estimated monthly or

\footnotetext{
${ }^{1}$ The reason to use origination volume instead of the number of originations is that the later is not disaggregated by age, credit score or relative income. The correlation between origination volume and number of originations is very high, around 0.97 .
} 


\begin{tabular}{lrr}
\hline Regulation & SD(Pr) & SD(Pr|Loan-type $)$ \\
\hline HEOAPEL & 0.0057 & 0.0034 \\
HEOACalc & 0.0260 & 0.0085 \\
HOEPA08 & 0.0157 & 0.0071 \\
MDIA & 0.0819 & 0.0212 \\
MDIA2 & 0.0103 & 0.0068 \\
CompBan & 0.0186 & 0.0128 \\
SAFE & 0.0418 & 0.0153 \\
AdRuleFTC & 0.0361 & 0.0120 \\
\hline
\end{tabular}

Table 8: SD of estimated probabilities within regulation year

quarterly origination volume as weights for aggregating complementary time series to year level.

HMDA data suffers from the same problem, only the year of origination is available. Unfortunately, there are no public statistics about mortgage applications with higher time precision. Regarding the probability of a regulation being in effect at the time of loan application, I assumed that loan applications are uniformly distributed along the year. 


\section{References}

Agarwal, Sumit, Itzhak Ben-David, and Vincent Yao. 2017. "Systematic Mistakes in the Mortgage Market and Lack of Financial Sophistication.” Journal of Financial Economics 123 (1):42-58. https://doi.org/10.1016/j.jfineco.2016.01.028.

Anthony Joseph Damico. n.d. Lodown: R Package to Download and Prepare Publicly-Available Microdata (version 0.1.0). http://asdfree.com/.

Armstrong, Mark. 2015. "Search and Ripoff Externalities." Review of Industrial Organization 47 (3):273-302. https://doi.org/10.1007/s11151-015-9480-1.

Board of Governors of the Federal Reserve System (US). n.d. "Treasury Constant Maturity Rate Series." Accessed May 5, 2018. https://fred.stlouisfed.org/.

Bordalo, Pedro, Nicola Gennaioli, and Andrei Shleifer. 2012. "Salience Theory of Choice Under Risk." The Quarterly Journal of Economics 127 (3):1243-85. https://doi.org/10.1093/qje/qjs018.

2013. "Salience and Asset Prices." American Economic Review 103 (3):623-28.

https://doi.org/10.1257/aer.103.3.623.

Carlin, Bruce I. 2009. "Strategic Price Complexity in Retail Financial Markets." Journal of Financial Economics 91 (3):278-87. https://doi.org/10.1016/j.jfineco.2008.05.002.

Carlin, Bruce Ian, and Gustavo Manso. 2011. "Obfuscation, Learning, and the Evolution of Investor Sophistication." The Review of Financial Studies 24 (3):754-85. https://doi.org/10.1093/rfs/hhq070.

Conlisk, John. 1996. “Why Bounded Rationality?” Journal of Economic Literature 34 (2):669-700. https://www.jstor.org/stable/2729218.

Consumer Financial Protection Bureau. n.d. "Consumer Credit Trends." Accessed May 25, 2018. https://www.consumerfinance.gov/data-research/consumer-credit-trends/.

DellaVigna, Stefano, and Ulrike Malmendier. 2004. "Contract Design and Self-Control: Theory and Evidence.” The Quarterly Journal of Economics 119 (2):353-402.

https://doi.org/10.1162/0033553041382111.

Edelman, Benjamin, and Julian Wright. 2015. "Price Coherence and Excessive Intermediation." The Quarterly Journal of Economics 130 (3):1283-1328. https://doi.org/10.1093/qje/qjv018.

Eliaz, Kfir, and Ran Spiegler. 2006. "Contracting with Diversely Naive Agents." The Review of Economic Studies 73 (3):689-714. https://doi.org/10.1111/j.1467-937X.2006.00392.x.

Ellison, Glenn. 2005. "A Model of Add-on Pricing." The Quarterly Journal of Economics 120 (2):585-637. https://doi.org/10.1093/qje/120.2.585.

Federal Financial Institutions Examination Council. n.d. "HMDA \& PMIC Data Products." Accessed August 20, 2018. https://www.ffiec.gov/hmda/hmdaproducts.htm.

Federal Financial Institutions Examination Council(FFIEC). n.d. "Loan Application Register(LAR) of Loans Subject to the Home Mortgage Disclosure Act(HMDA).” Accessed July 4, 2018. https://www.ffiec.gov/hmda/.

Federal Reserve. n.d. "Bulk Data - National Information Center." Federal Financial Institutions Examination Council. Accessed August 20, 2018. https://www.ffiec.gov/npw/FinancialReport/DataDownload. 
Federal Reserve Board. n.d. "Survey of Consumer Finances of 2013.” Accessed April 27, 2018. https://www.federalreserve.gov/econres/scf_2013.htm.

Gabaix, Xavier. 2014. “A Sparsity-Based Model of Bounded Rationality.” The Quarterly Journal of Economics 129 (4):1661-1710. https://doi.org/10.1093/qje/qju024.

—. 2017. "Behavioral Inattention.” Working Paper 24096. National Bureau of Economic Research. https://doi.org/10.3386/w24096.

Gabaix, Xavier, and David Laibson. 2006. "Shrouded Attributes, Consumer Myopia, and Information Suppression in Competitive Markets." The Quarterly Journal of Economics 121 (2):505-40. https://doi.org/10.1162/qjec.2006.121.2.505.

Gabaix, Xavier, David Laibson, Guillermo Moloche, and Stephen Weinberg. 2006. "Costly Information Acquisition: Experimental Analysis of a Boundedly Rational Model.” American Economic Review 96 (4):1043-68. https://doi.org/10.1257/aer.96.4.1043.

Gennaioli Nicola, Shleifer Andrei, and Vishny Robert. 2015. "Money Doctors." The Journal of Finance 70 (1):91-114. https://doi.org/10.1111/jofi.12188.

Grubb, Michael D. 2015. "Consumer Inattention and Bill-Shock Regulation.” The Review of Economic Studies 82 (1):219-57. https://doi.org/10.1093/restud/rdu024.

Gurun Umit G., Matvos Gregor, and Seru Amit. 2016. “Advertising Expensive Mortgages.” The Journal of Finance 71 (5):2371-2416. https://doi.org/10.1111/jofi.12423.

Gürkaynak, Refet S., Brian Sack, and Jonathan H. Wright. 2007. "The US Treasury Yield Curve: 1961 to the Present." Journal of Monetary Economics 54 (8):2291-2304.

Heidhues, Paul, and Botond Köszegi. 2017. "Naïveté-Based Discrimination." The Quarterly Journal of Economics 132 (2):1019-54. https://doi.org/10.1093/qje/qjw042.

Heidhues, Paul, Botond Kőszegi, and Takeshi Murooka. 2016. "Exploitative Innovation.” American Economic Journal: Microeconomics 8 (1):1-23. https://doi.org/10.1257/mic.20140138.

- 2017. "Inferior Products and Profitable Deception." The Review of Economic Studies 84 (1):323-56. https://doi.org/10.1093/restud/rdw037.

Inderst, Roman, and Marco Ottaviani. 2012. "How (Not) to Pay for Advice: A Framework for Consumer Financial Protection.” Journal of Financial Economics 105 (2):393-411. https://doi.org/10.1016/j.jfineco.2012.01.006.

Lumley, Thomas. n.d. Survey: Analysis of Complex Survey Samples in R (version 3.33).

Moody’s. n.d. "Moody’s Corporate Bond Yield Averages.” Accessed May 8, 2018. https://fred.stlouisfed.org/.

Philippon, Thomas. 2015. "Has the US Finance Industry Become Less Efficient? On the Theory and Measurement of Financial Intermediation." American Economic Review 105 (4):1408-38. https://doi.org/10.1257/aer.20120578.

Piccione, Michele, and Ran Spiegler. 2012. "Price Competition Under Limited Comparability." The Quarterly Journal of Economics 127 (1):97-135. https://doi.org/10.1093/qje/qjr053.

Spiegler, Ran. 2016. "Choice Complexity and Market Competition." Annual Review of Economics 8 (1):1-25. https://doi.org/10.1146/annurev-economics-070615-115216.

Stango, Victor, and Jonathan Zinman. 2011. "Fuzzy Math, Disclosure Regulation, and Market Outcomes: Evidence from Truth-in-Lending Reform." The Review of Financial Studies 24 (2):506-34. 
https://doi.org/10.1093/rfs/hhq089.

U.S. Bureau of Labor Statistics. n.d. "Consumer Price Index for All Urban Consumers.” Accessed June 17, 2018. https://fred.stlouisfed.org/.

U.S. Department of the Treasury. n.d. "High Quality Market (HQM) Corporate Bond Spot Rate Series." Accessed April 21, 2018. https://fred.stlouisfed.org/.

Woodward, Susan E., and Robert E. Hall. 2012. "Diagnosing Consumer Confusion and Sub-Optimal Shopping Effort: Theory and Mortgage-Market Evidence." American Economic Review 102 (7):3249-76. https://doi.org/10.1257/aer.102.7.3249. 